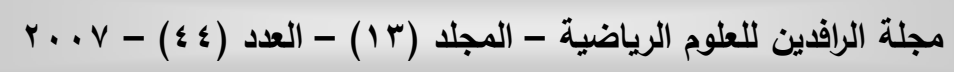

العلاقة بين النشاط المفرط والكفاءة الإدراكية الحركية لاى التلاميذ المفرطي النشاط والأصحاء للصف الثالث الابتدائي

م.م فادية محروس جرجيس أ.م .د ليث محمد داؤد البنا

جامعة الموصل / كلية التربية الرياضية

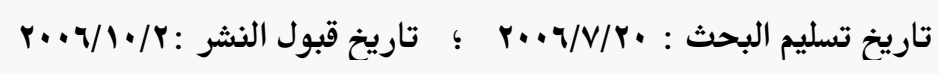

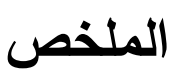

هدف البحث التعرف على:-

- العلاقة بين النشاط المفرط والكفاءة الإدراكية الحركية للدى التلاميذ مفرطي النشاط

$$
\text { للصف الثالث الابتدائي. }
$$

- العلاقة بين النشاط غير المفرطوالكفاءة الإدراكية الحركية لاى التلاميذ الأصحاء للصف

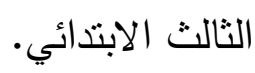

لقد اقتصر البحث على تلاميذ الصف الثالث الابتدائي من مدرسة الإيثار الابتدائية

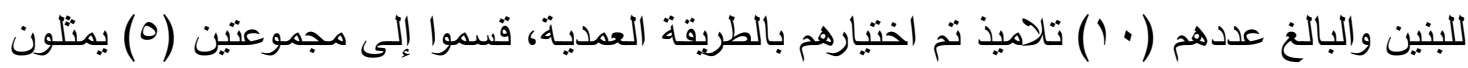

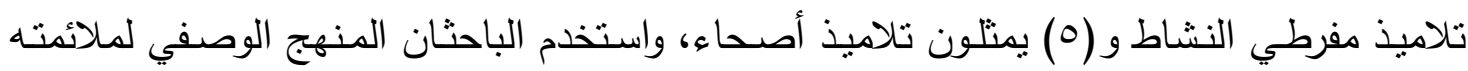

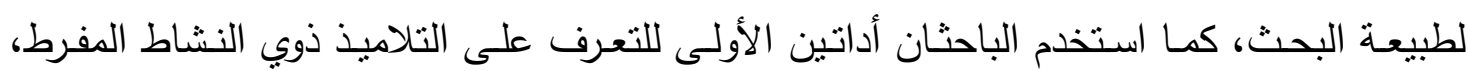

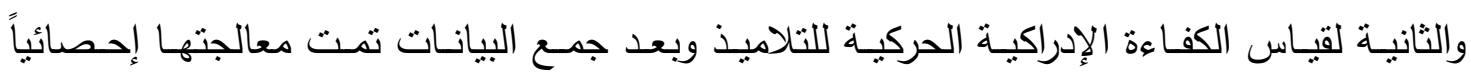

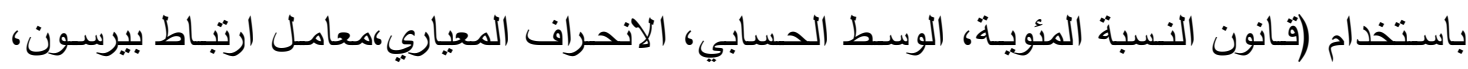
اختبار (T-Test)، معامل الارتباط البسيط). وأسفرت النتائج عن: ا. وجود علاقة غير معنوية بين النشاط المفرط والكفاءة الإدراكية الحركية لدى التلاميذ المفرطي النشاط للصف الثالث الابتدائي. r. وجود علاقة معنوية بين النشاط غير المفرط والكفاءة الإدراكية الحركية لدى التلاميذ الأصحاء. وأوصى الباحثان عدة توصيات منها: 


$$
\begin{aligned}
& \text { ا. التشخيص المبكر للتلاميذ المفرطي النشاط ومحاولة التعاون مع الآباء في اعتماد برامج معينة } \\
& \text { تهدف الى تتمية قدراتهم الثخصية من خلال زبادة الثقة بأنفسهم وبإمكانياتهم مما يساعد في } \\
& \text { تعديل السلوك غير المرغوب فيه ويزيد من مقدرتهم على تقبل المواد النظرية. } \\
& \text { r. فسح المجال أمام التلاميذ خلال دروس التربية الرياضية في التعبير عن ذاتهم وامكاناتهم الحركية } \\
& \text { ورغباتهم، بما يوفر للنلميذ بيئة ذاتية تفاعلية مبنية على الحرية الحركية بعيدا عن التقليدية في } \\
& \text { التنفيذ الحركي } \\
& \text { ب. توعية الآباء بأهمية الهوايات والرباضـة البدنية والتروبح عن النفس او الاثتراك في الأنشطة } \\
& \text { المدرسية والتربيـة الفنيـة والـرحلات المدرسية في مساعدة التلميذ في تتميـة شخصيته نفسيا } \\
& \text { واجتماعيا ومن ثم تعديل سلوكه ذاتيا. }
\end{aligned}
$$

\section{ABSTRACT \\ The relation between over-activity and the dynamic perceptive efficiency of over-active and Healthy third grade students \\ Researchers}

Assist. Prof.Laith Al bana

\section{Mosul University / College of Physical Education}

Assist-teacher :Fadia Mahroos Jarjis

The stuty aims at finding out the the following

a- The relationship between over- activity and the dynamic perceptive efficiency of over - active third grade students.

b- The relationship between lesser activity and the dynamic perceptive efficiency of third grade students.

The study was limited to ten grade students from Al- Ethar primary school. Whom they were intentionally chosen then the divided into two groups each consisted of five students .First group presented over-active students while the other ore presented Healthy students. The researcher used the descriptive method for it is suitablty for the nature of the research. The resea rchers also used two instruments, one for identifying over- active students , and the other for measuring the dynamic perceptive efficiency for the students. The dadta were collected and statistically treated by using 
percentage ratio smean standard deviation pearson correlation coefficient, $\mathrm{T}$ test and simple correlation coefficient.

The results were as follows.

1.The is non significant correlation between over-activity and the dynamic perceptive efficiency of the over-active students.

2.There is a significant correlation between the lesser-activity and the dynamic perceptive efficieny of the ordinary students.

The researchers recommend:

1.Early identification for those who are over- active students should be done ,mean while, an attempt should be taken to help their parents to establish programmes that would develop students personal abilities through increasing their self -confidence and potential which would straighten any unwanted behavior and increase their abilities to understand scienfic subjects .

2. Letting the students to express themselves and physical abilites, and their desires lessons, which provide wid the student with an interactive environment based upon physical freedom, away from classic use of physical performance .

3. Educating parents on the importance of developing students hobbies and encouraging sports and self- entertainment, or encouraging the students to develop his own personality, both spiritually and socially, which, as a result, would straighten the students behavior . instead of wasting of their time . 
تعد مرحلة الطفولة من المراحل المهمة والأساسية في تكوين شخصية الفرد وتحديد معالمها،

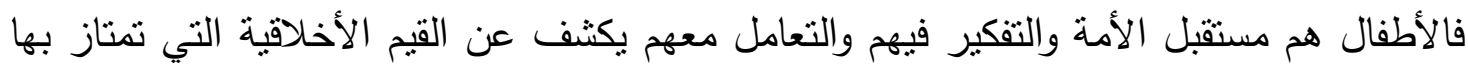

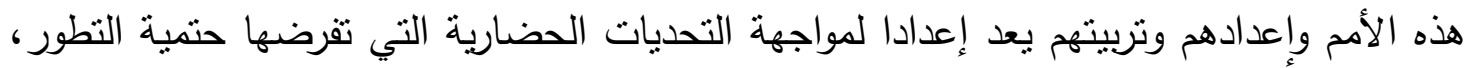
اذ أثتبت الدراسات ان الطفولة السعيدة ومنها طفولة المرحلة الابتدائية تؤدي الى مستقبل باهر

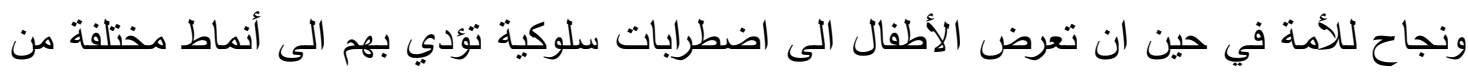
المشكلات السلوكية تترك فيما بعد أثارها على مستقبلهم ومن ثمة الثة على مستقبل أوطانهم (الحمداني، .$(0, r . . \varepsilon$

لقد شغل موضوع المشكلات السلوكية الباحثين وما زال يشغلهم ولاسيما في عصر يتلقى فيه

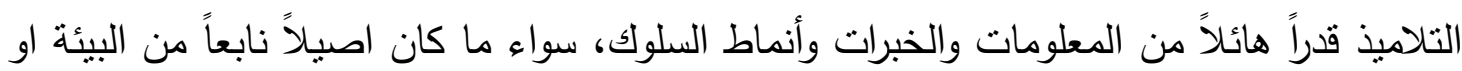

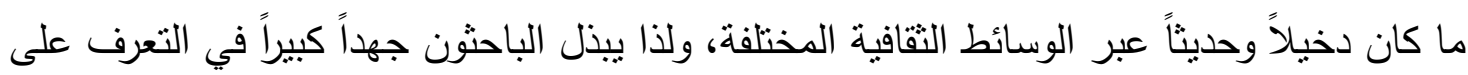

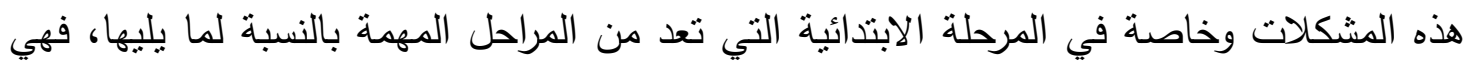

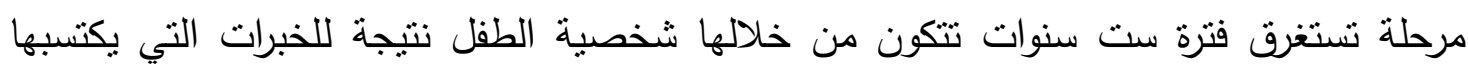

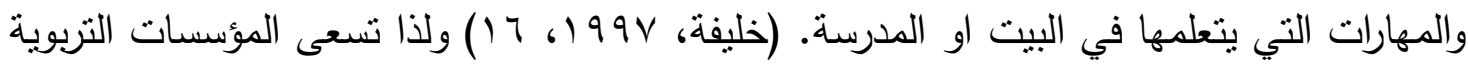

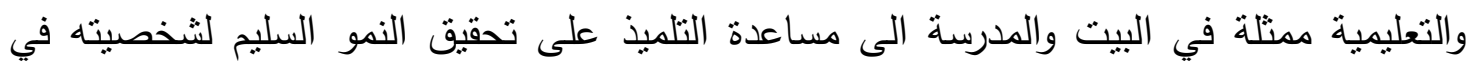
مختلف المجالات الجسمية والنفسية والاجتماعية، ويواجه الطفل اليوم في العالم المعاصر وفي طلئل

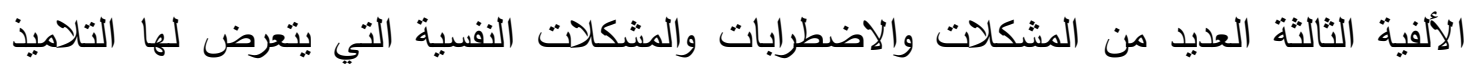
كغيرهم في المراحل النمائية الأخرى، كاضطراب الحركة، وقلة الانتباه وتتتته وانعدام التركيز

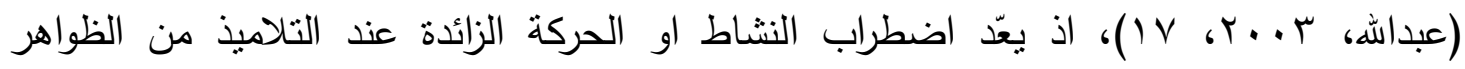

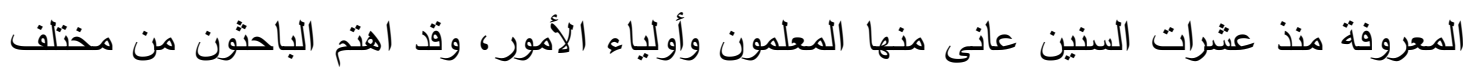

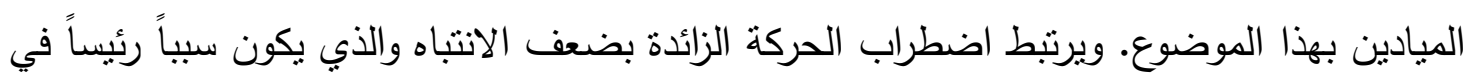

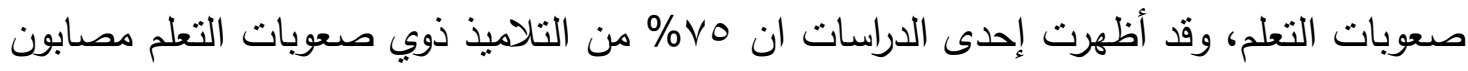
باضطرابات النشاط او الحركة الزائدة، وان ه\% من تلاميذ المدرسة الابتدائية يعانون من اضطراب 
الحركة الزائدة ومعظمه من الذكور، ولابد من النظر الى هذا الاضطراب على انه مشكلة سلوكية لها تأثير مباشر على التلميذ ومستقبله.

\section{(المعايطة، (1997)}

ويتفق علماء النفس والمهتمون بتتمية الطفل على أهية الخبرات الحركية باعتبارها مصدرا

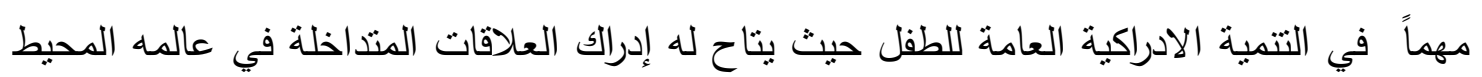

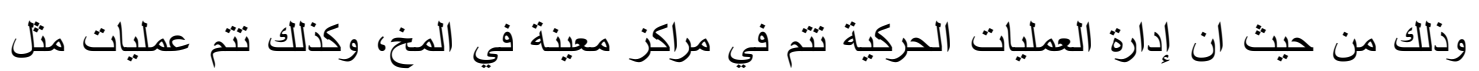

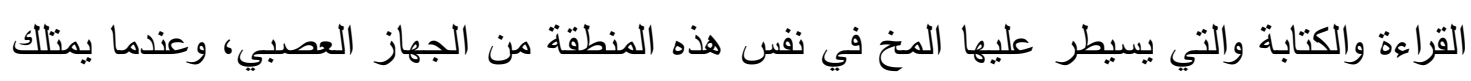

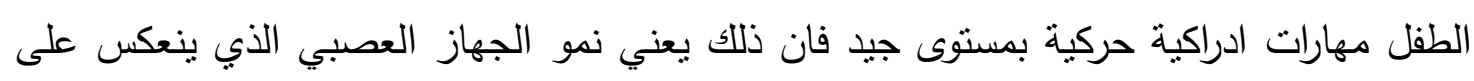

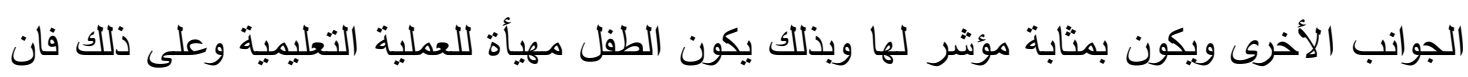

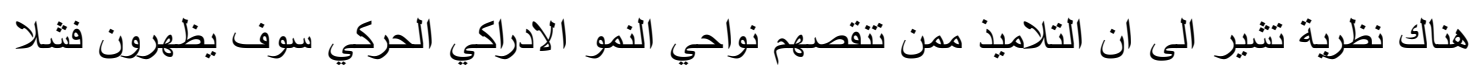

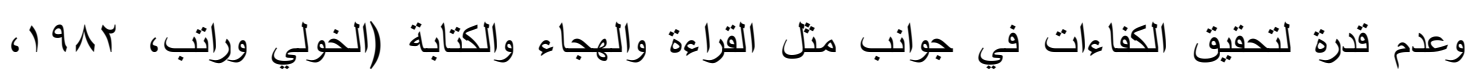

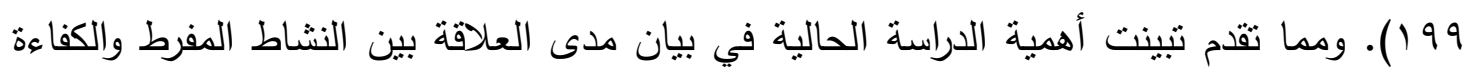

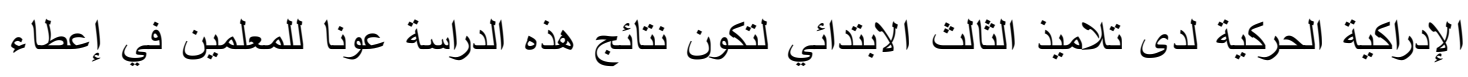

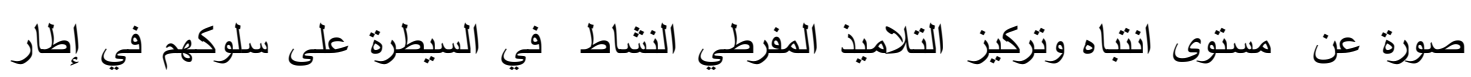

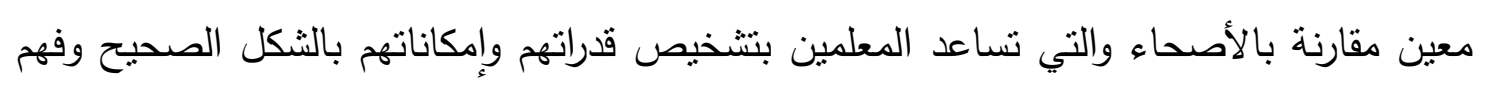
سلوكهم وقابليتهم المعرفية.

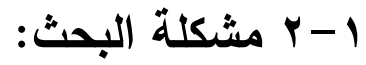

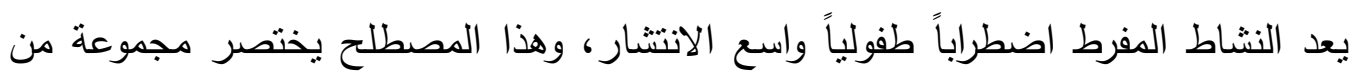

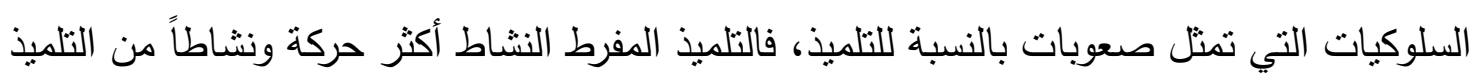

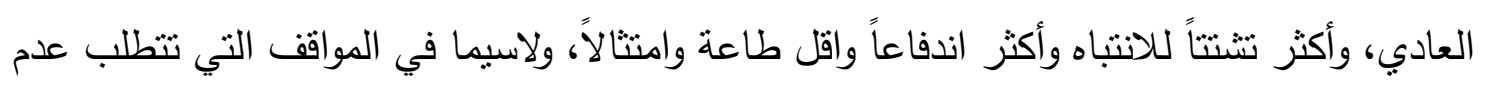

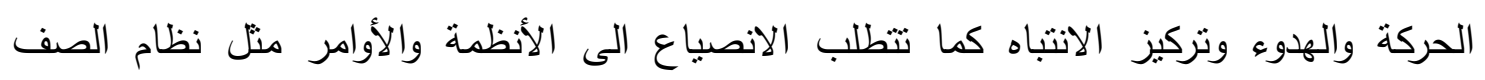

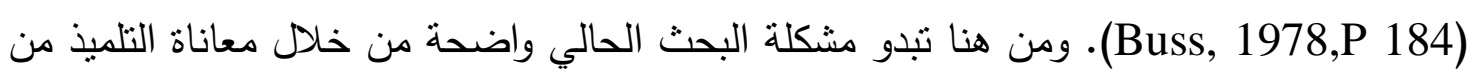

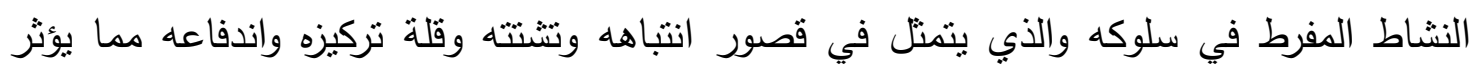

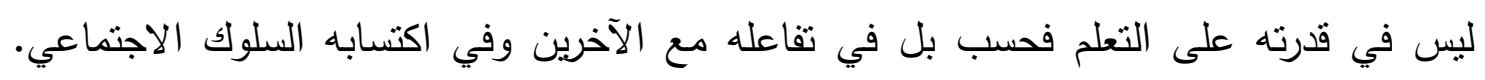
فضلا عن المعاناة الني يشعر بها والداه من خلال هذه السلبيات في السلوك مما يؤثر على العلاقة الألى

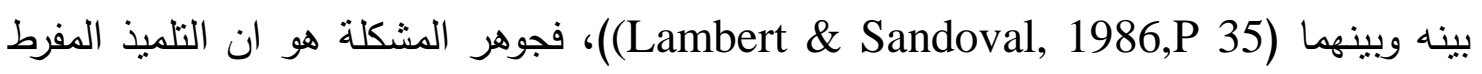

r 
النشاط هو طفل يتحرك كثيراً بدرجة اكبر من غيره ممن هم في العمر الزمني نفسه، واغلب هذه

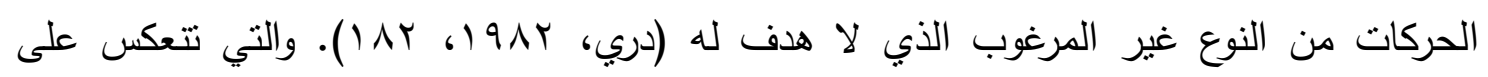

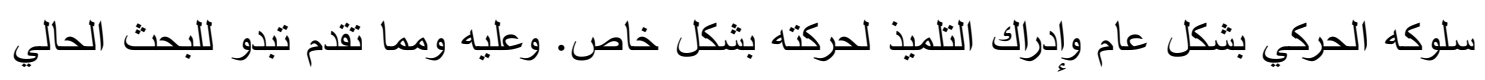

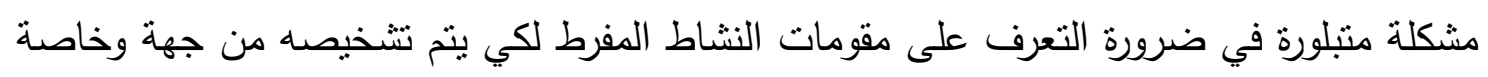

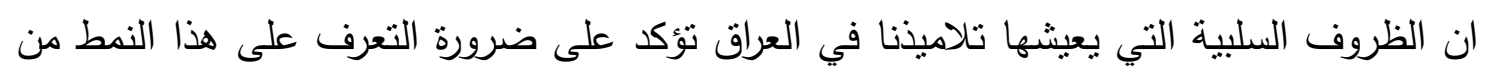

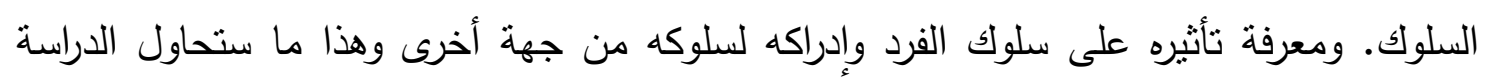
الحالية من تأكيده او نفيه من خلال النتائج التي سيتم التوصل إليها.

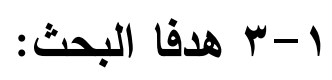

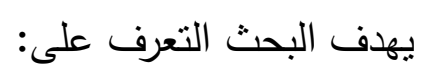

- العلاقة بين النشاط المفرط والكفاءة الأدراكية الحركية لاى التلاميذ مفرطي النشاط للصف

$$
\text { الثالث الابتدائي. }
$$

- العلاقة بين النشاط غير الدفرط والكفاءة الأدراكية الحركية لدى التاميذ الأصحاء للصف

$$
\text { ا - الثالث الابتدائي. }
$$

- وجود علاقة غير معنوية بين النشاط المفرط والكفاءة الأدراكية الحركية لدى التلاميذ مفرطي النشاط للصف الثالث الابتدائي.

- - وجود علاقة معنوية بين النشاط غير المفرط والكفاءة الأدراكية الحركية لاى التلاميذ الأصحاء للصف الثالث الابتدائي.

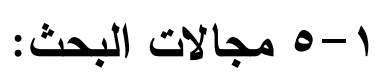

1-0-1 المجال البشري: تلاميذ الصف الثالث الابتدائي في مدرسة الإيثار للانبن في محافظة

$$
\text { نينوى. }
$$

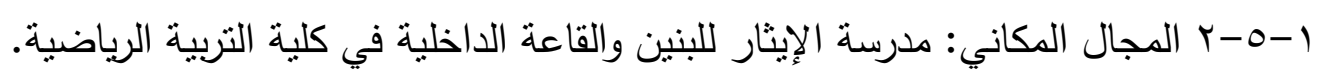

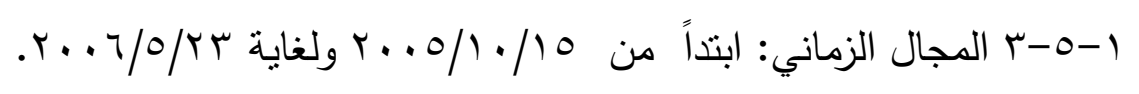


(النشاط المفرط (Hyperactive)

$$
\begin{aligned}
& \text { وقد عرفه كل من: }
\end{aligned}
$$

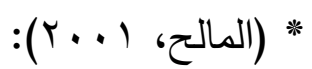

بأنه حركات جسمية تفوق الحد الطبيعي المعقول، المتميزة بالاندفاعية وتتشت الانتباه فضلا

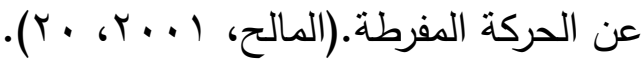

$$
\begin{aligned}
& \text { * (طنطاوي وعجلان، } 990 \text { (1): }
\end{aligned}
$$

اضطراب سلوكي ينتثل في النشاط الحركي ونقص وقصور في مدة الانتباه والاندفاع أهم

$$
\text { مكوناته.(طنطاوي وعجلان، } 1990 \text { 19، 10). }
$$

r.الطفل المفرط النشاط (Hyperactive Child):

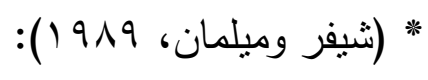

هو الطفل الذي يظهر حركات جسمية تفوق الحد الطبيعي او المعقول، وتظهر من خلال النشاط غير الملائم وغير الموجه بالمقارنة مع سلوك الطفل النشط الذي تتسم فعالياته بأنها هادفة

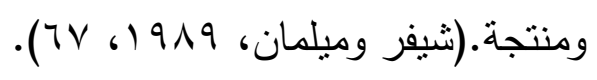

:(Williams \& Stith, 1980) *

هو الطفل الذي يظهر مستوى من النشاط الحركي اليومي اوضح بكثير من ذلك الذي يظهر

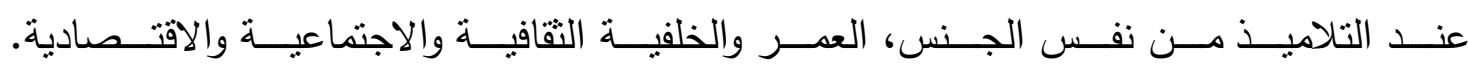
(Williams \& Stith, 1980,p. 3)

* أما التعريف الإجرائي للطفل المفرط النشاط فقد عرفه الباحثان إجرائيا: بأنه الطفل الذي تزيد درجته عن المتوسط النظري في استبيان للمظاهر السلوكية الذي أعدته

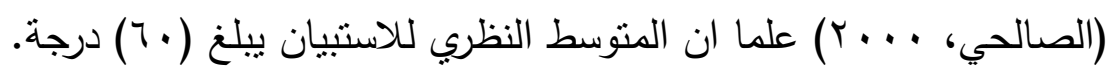




$$
\text { * وقد عرفها كل من: (الخولي وراتب، ع9 1 )): }
$$

بانها "قدرة الفرد في إدارة المعلومات التي تاتي له من خلال الحواس وعملية تشغيل المعلومات وردة الفعل في ضوء السلوك الحركي الظاهري" .

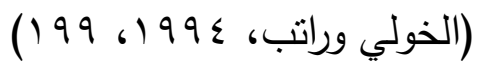

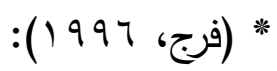

هي قدرات تعليمية تعتمد على الحركة كوسيلة لان يأخذ المتعلم مكانه مع وجود تفاعل بين البيانات الحركية والبيانات الأدراكية بحيث تتمو كلا القدرتين جنبا الى جنب لدى الطفل. (

* أما التعريف الإجرائي للكفاءة الأدراكية الحركية فقد عرفه الباحثان إجرائيا: بأنه مقدار الوقت الذي يحصل عليه الطفل في اختبار (طريق الموانع الادراكي- الحركي) المصمم من قبل (Nelson, 1983) والمترجم من قبل (فرج، بـ919). r. الإطار النظري والدراسات السابقة:

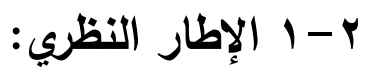

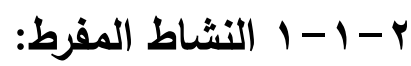

لقد كان موضوع النشاط الدفرط مثار اهتمام الباحثين على مدى قرن وقد كانت أول إنثارة الى النشاط الدفرط عام r .9 (، عندما قدم طبيب الإنكليزي (Still ) سلسلة من الدحاضرات عرض فيها

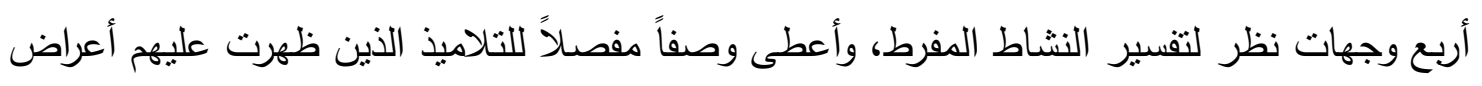
النشاط الدفرط نتيجة التعرض لأضرار كبيرة وجروح في الدماغ أدت الى تلف الدماغ، وكذللك نتيجة

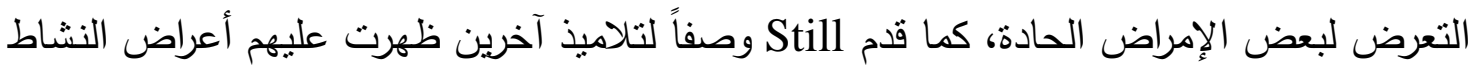

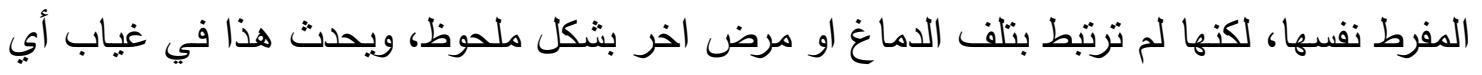
ضعف في الجهاز العصبي المركزي او أي مرض جسدي، وقد وصف الطبيب Still هؤلاء التلاميذ

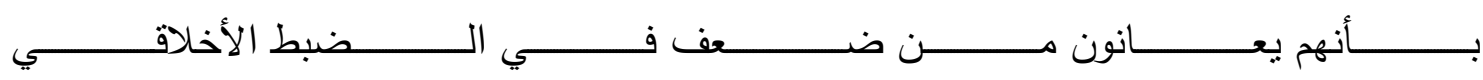
Ross \& Ross, 1976, P.P14-15). الا انه مع التقدم في طرائق التشخيص والطب النفسي، 
وجد ان هذه الأعراض قد نظهر عند تلاميذ لا يعانون من أي تلف في خلايا المخ، وعليه سقطت نظرية علاقة هذا الاضطراب بضمور خلايا المخ (المنياوي، ب ...r، ()، وقد تتباين صور النشاط الزائد حسب المرحلة العدرية من نشاط حركي واضتح الى تململ. وبشكل عام، يظهر في الطفولة كحركة دائبـة غير هادفـة، إذ ينتقل مـن موضـوع او مكان الى أخر، وكأن هنـالك من يدفعـه نحو

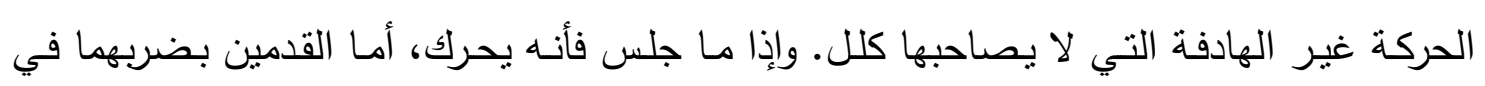
الأرض، او اليدين بتحريكها في أي اتجاه. ويجب ملاحظة انهه مع التقدم في العدر نحو المراهقة والرشد تكون الأعراض في هذا الجانب أكثر تخفيفاً. إذ تتجسد لا في حركة او نشاط ظاهر، بل غالباً - في تململ وملل وصعوبة في البقاء ساكناً فنرة طويلة. ينعكس هذا النشاط الزائد على مجالات عديدة (Wender, 2000,P 85). وعليه يجب ان يؤخذ بعين الاعتبار ان الأعراض تتباين في إثكالها وصورها من فرد الى أخر، مـع تباين في الحدة، إذ تكون واضحة جداً في الحالات الحادة، وأقل وضـوحاً في الحسالات المتوسطة والأقل منهـا. وبـرى البعض ان كل تلك المظاهر بأبعادها الفرعية الرئيسة نتاج عامل سلوكي او عامل نفسي -عصبي-معرفي (Barkley, 1997,P 65) كما ان معظم الدراسات أثبتت ان غالبية التلاميذ ذوي اضطراب الحركة الزائدة لديهم مشاكل تعليمية، وان تحصيلهم الدراسي ضعيف وان كلا من المعالجين والتربوبين قد لاحظوا ان هؤلاء التلاميذ مختلفون في أدائهم التعليمي عن التلاميذ العاديين، فأحيانا يكون أداؤهم ممتازاً وأحيانا أخرى يكون منخفضاً جدا (المعايطة، 997 19 VV). ويوجد تصنيفان رئيسان للنشاط المفرط أحداهما يركز على جانب الطب النفسي والأخر على جانب النفس-تربوي.

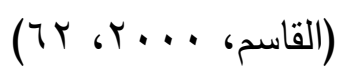

r - r- r r الطقل المفرط النشاط:

ان من المشكلات الأكثر إلحاحا في مدارسنا وجود فئة من التلاميذ يتصفون بفرط النشاط فقد بات موضـوع النشاط الزائد من المشكلات التي يطول بحثها، وبالتأكيد هي واحدة من أعظم الثكاوى الثائعة بين الوالدين والمعلمين. وتقريباً الإباء والأمهات يشكون من ان لدى تلاميذهم نشاطاً زائداً. وتم تلخيص الأنشطة الزائدة مبدئياً كمشكلة مرحلـة الطفولة الوسطى، ولكنها ألان عرفت كمشكلة تبدأ قبل السنة السابعة. ويعد هذا الاضطراب أكثر انتشاراً في الذكور عنه في الإناث بنسبة 
ا:؛؛، وانه غالباً ما يكون لواحد او أكثر من الأمراض النفسية المصاحبة، وتختلف نسبة حدوثه من

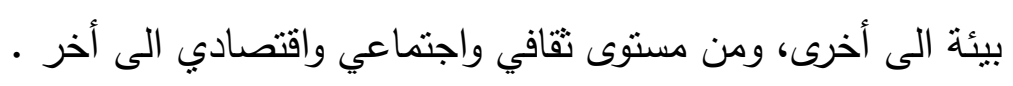

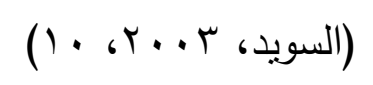

اذ يتصف التلاميذ المصابون بهذا الاضطراب بكونهم لا يلبثون على حال واحدة من الناحية الحركية بل أنهم يجدون صعوبة في ضبط حركتهم، الأمر الذي يسبب كثيرا من الإزعاج للمحيطين

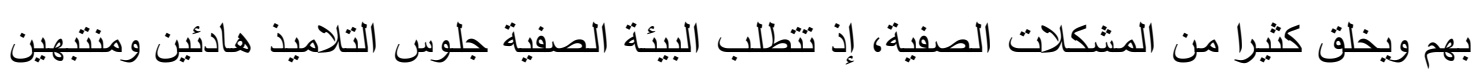

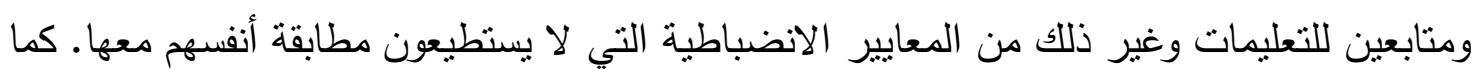

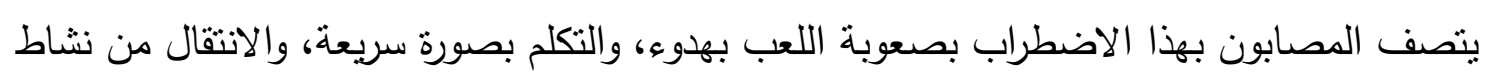

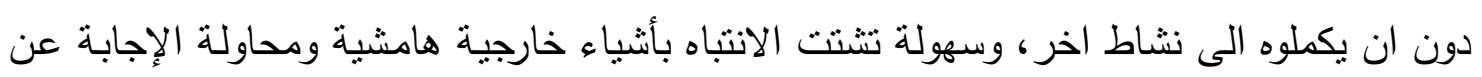

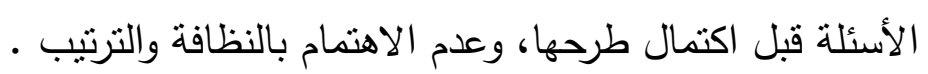

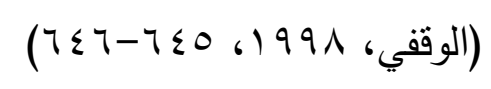

\section{r r r r الكفاعة الإدراكية الحركية:}

تعد الوظائف الحركية والإدراكية من الوظائف الحيوية التي اهتم بها علماء النفس اهتماما

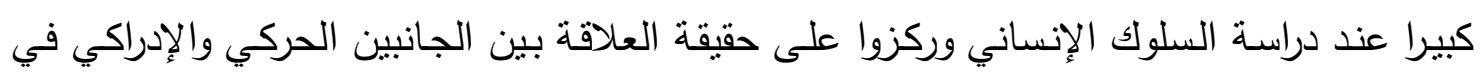
السلوك الإنساني، ويرى بياجيه ان الحركة تتأثز بالإدراك كما يتأثر الإدراك بالحركة ولا يمكن الفصل بلئل

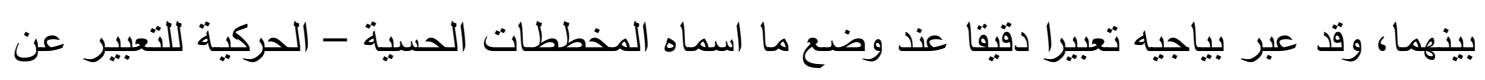
حقيقة التكامل الادراكي - الحركي في سلوك الطفل كما يؤكد ان أي تمييز بين كل من الوظائف الحركية والوظائف الادراكية ليس أكثر من استجابة لحاجات البحث العلمي. وتثثير الدراسات النظرية (Richard, 1991) ، (Dauer \& Pangrazi, 1979)، (Baumgartner \& Jackson, 1975)

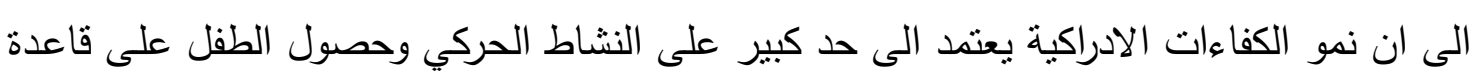

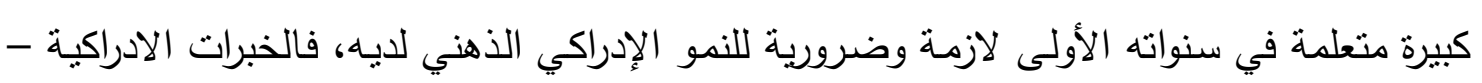

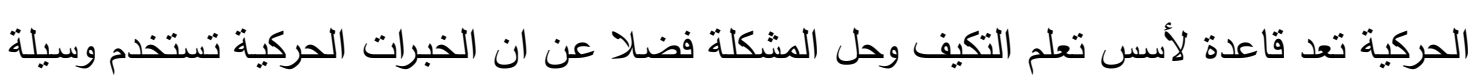

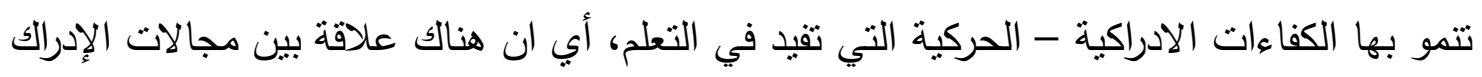

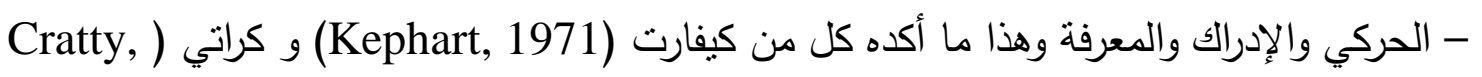


$\varepsilon$

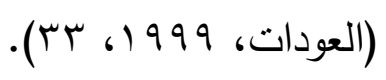

وتعتمد الكفاءة الادركية - الحركية على العديد من العوامل التي تبنت وجودها وهي:

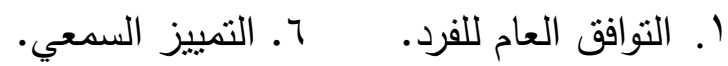

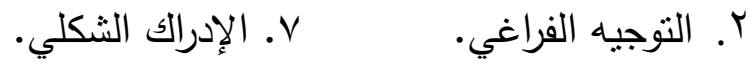

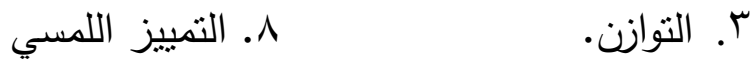

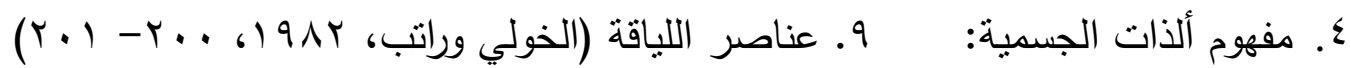
○. التوافق بين (اليد والعين) و (العين والقدم).

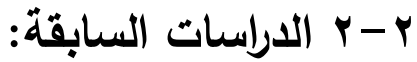

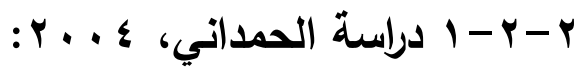

"اثر برنامج تدريبي في توجيه النثاط المفرط لاى تلاميذ المرحلة الابتدائية"

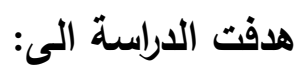
1 ا ـ تشخيص التلامبذ ذوي النشاط المفرط.

r.التعرف على اثر برنامج تدريبي في توجيه النشاط المفرط لدى تلاميذ المرحلة الابتدائية.

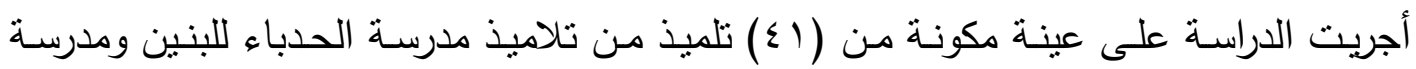
الغسانية المختلطة تم اختبارهم بالطريقة العمدية، واستخدمت الباحثة قائمة المظاهر السلوكية المعدة

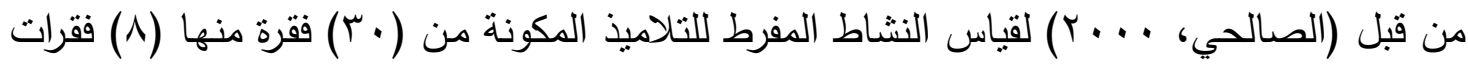
في المجال الجسمي والحركي و(ب () فقرة في المجال النفسي والاجتماعي و(· () فقرات في المجال العقلي والمعرفي، ولتصحيح قائهـة المظاهر السلوكية أعطيت ثلاث درجات للبديل الأول (كثيراً)

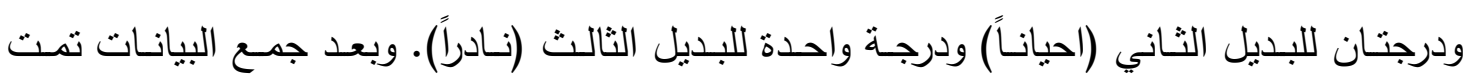

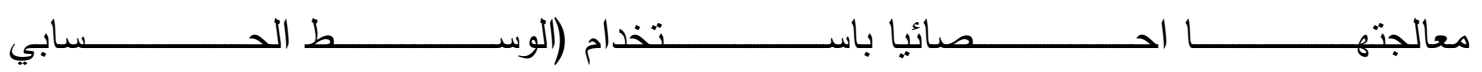

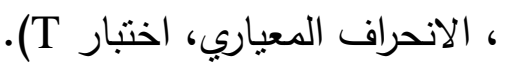


ا ـ فاعلية البرنامج التعليمي الذي اعدته الباحثة في خفض مستوى النشاط الدفرط لدى التلاميذ

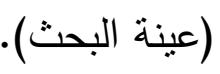

r. عدم وجود فروق بين التلاميذ المفرطي النشاط لمتغير الصف الدراسي (الثالث، الرابع،

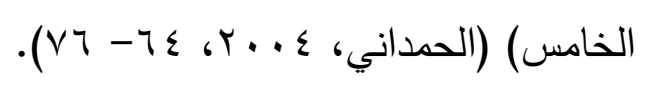

إن

"اثر برنامج مقترح للتربية الحركية في الكفاءة الإدراكية- الحركية لدى طلبة الصف الثالث

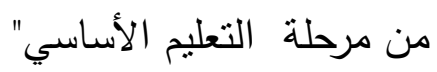

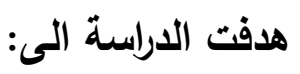

- الكثف عن اثر برنامج مقترح للتربية الحركية في الكفاءة الادراكية- الحركية للى طلبة

$$
\text { الصف الثالث من مرحلة التعليم الأساسي. }
$$

أجريت الدراسة على عينة مكونة من (TV) طالب وطالبة من طلبة الصف الثابلة الثالث الأساسي

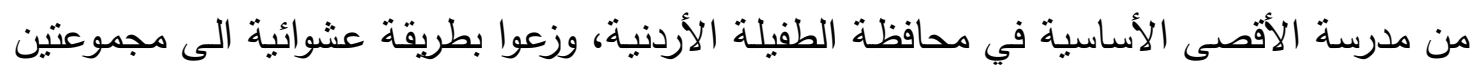

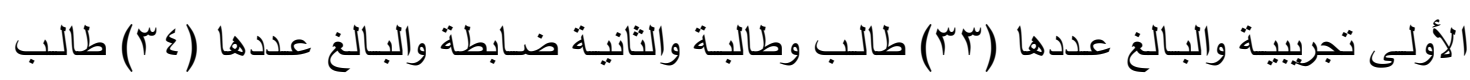

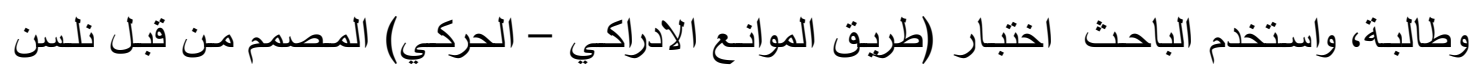

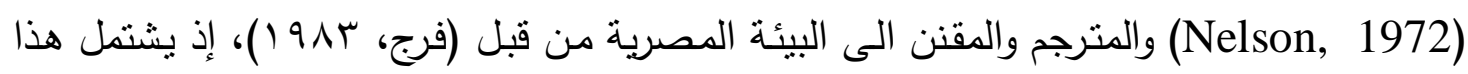
الاختبار على سبعة عناصر تختص بقياس (توافق العين والقدم وإلاحساس بالمكان وتمييز الإشكال

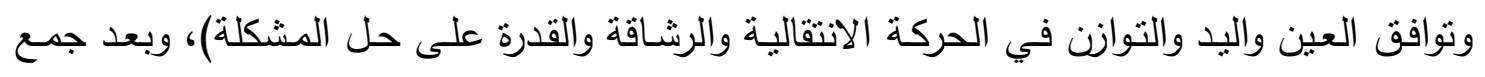

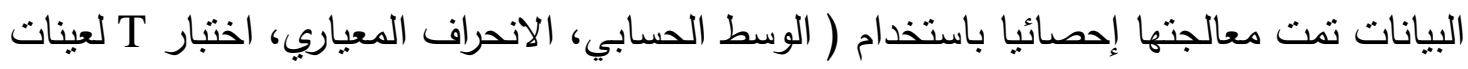

$$
\text { مرتبطة وغير مرتبطة). }
$$

1. ان البرنـامج المقترح للتربيـة الحركية ذو تأثثر فعال وايجابي في تتميـة الكفاءة الادراكيـة-

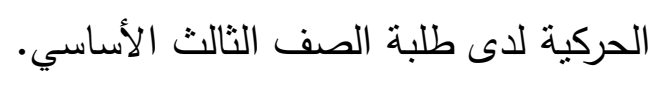

r. لا توجد فروق ذات دلالة إحصائية بين الذكور والإناث في تتمية الكفاءة الادراكية- الحركية

بعد تطبيق البرنامج المقترح للتربية الحركية.

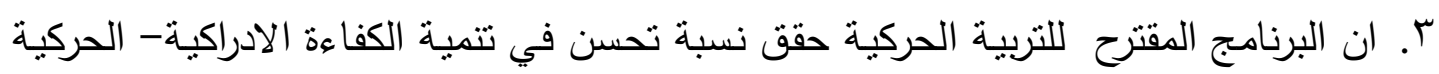
لاى الذكور أفضل من الإناث. 


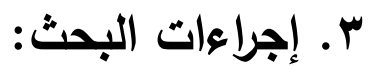 \\ r- 1- 1 منهج البحث:}

استخدم الباحثان المنهج الوصفي لملاءمته وطبيعة البحث.

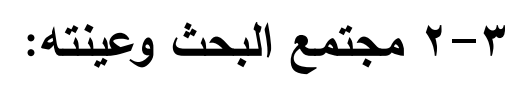

تمثل مجتمع البحث بتلاميذ الصف الثالث الابتدائي من مدرسة الإيثار الابتدائية للبنين

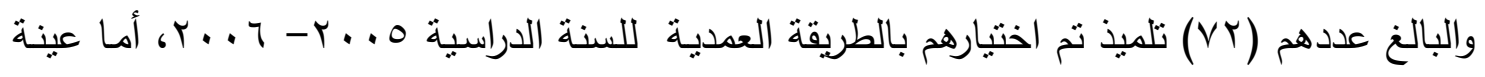

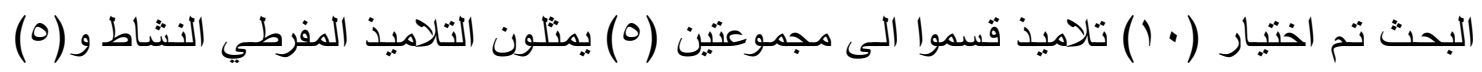

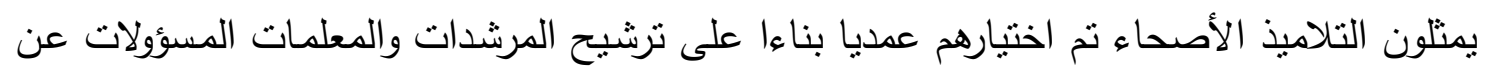

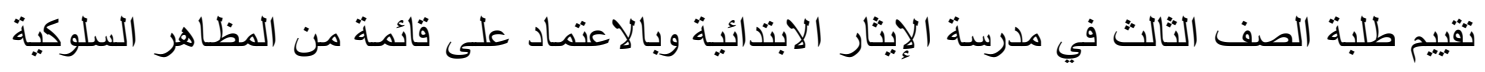
(أداة البحث) بعد استبعاد عدد من الطلبة لعدم تكافؤهم (الممارسين للرياضة، الراسبين والمؤجلين) فضلا عن عينة الثبات والتجارب الاستطلاعية. r-r تكافؤ مجموعتي البحث: r-r-1 التكافؤ في الطول: مقاسا بالسنتمتر (تم حسابه لأقرب سنتمتر). r-r-r التكافؤ في العمر الزمني: مقاسا بالثهر (تم حسابه لأقرب شهر). r-r-r التكافؤ في الكتلة: مقاسا بالكيلو غرام (تم حسابه لأقرب نصف كيلو غرام). r-r- 


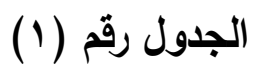

يبين المعالم الإحصائية وقيم (ت) المحسوية لتكافؤ التلاميذ المفرطي النشاط والأصحاء في المتغيرات الطول والعمر والكتلة والذكاء

\begin{tabular}{|c|c|c|c|c|c|c|c|}
\hline \multirow{2}{*}{ النتيجة } & \multirow{2}{*}{ قالمسموية } & \multicolumn{2}{|c|}{ التلاميذ الأصحاء } & \multicolumn{2}{|c|}{ التلاميذ المفرطي النشاط } & \multirow{2}{*}{ القياس } & \multirow{2}{*}{ المتغيرات المعالم الإحصائية } \\
\hline & & $\varepsilon^{ \pm}$ & س س & $\varepsilon^{ \pm}$ & سَ & & \\
\hline غير معنوي & $1, \times 19$ & $r, 1 \leqslant r$ & ד, & Y,OVV & re, T & سم سم & الطول \\
\hline غير معنوي & .,Or & r,oro & $11 \%, 4$ & Ү.११४ & 111,8 & شهر & العمر \\
\hline غير معنوي & $1,7 \leqslant 9$ & $\leq, \$ 90$ & rq, & $r, .40$ & ro,0 & كفم & الكتلة \\
\hline غير معنوي & l,arr & & rq & $\varepsilon, \varepsilon V Y$ & $r \varepsilon$ & درجة & الذكاء \\
\hline
\end{tabular}

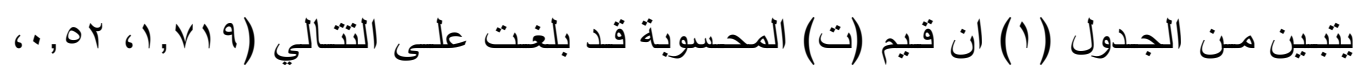

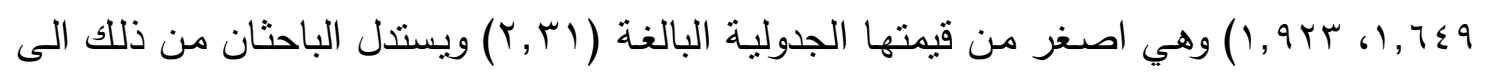

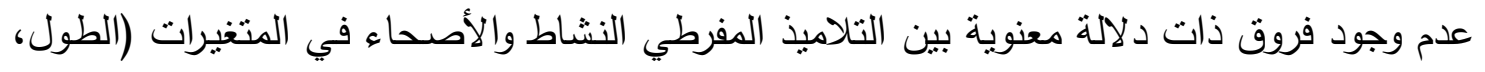

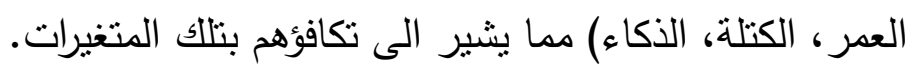
بنم اعتماد أداتين الأولى للتعرف على التلاميذ ذوي النشاط المفرط، والثانية لقياس الكفاءة

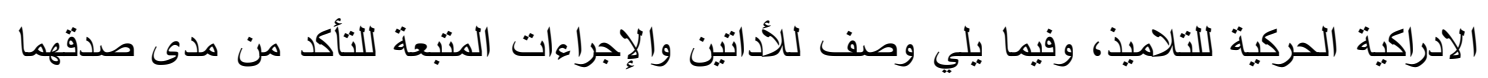
وثباتهما.

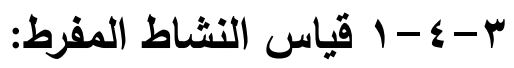

ان من متطلبات البحث الحالي وجود أداة لقياس النشاط الدفرط لدى تلاميذ الصف الثالث الابتدائي، وبعد إطلاع الباحثان على عدد من المقاييس والاختبارات في مجال النشاط الدفرط تم

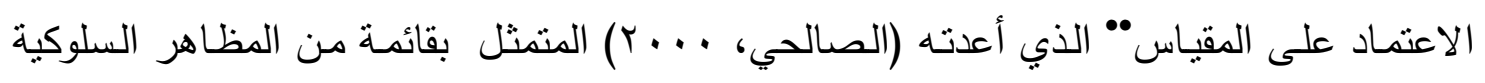


وذلك من حيث كونه أحدث المقاييس فضلا عن ملاعهته للبيئة العراقية ومناسبته لأعمار التلاميذ ومرحلتهم الدراسية في هذا البحث. r- - - 1-1 وصف المقياس:

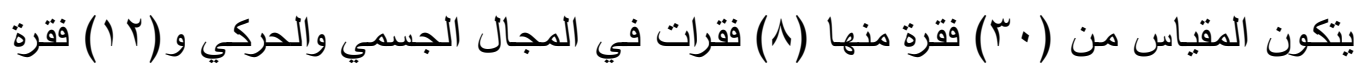
في المجال النفسي والاجتماعي و(· • () فقرات في المجال العقلي والمعرفي.

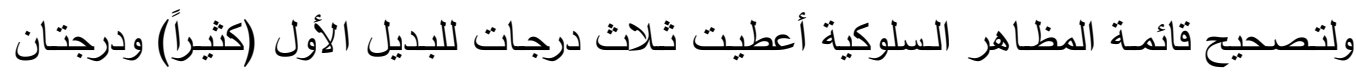

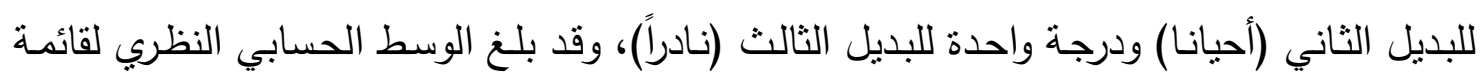
المظاهر السلوكية (• (7) درجة.

r- ب - ب قياس الكفاءة الإدراكية الحركية:

لغرض قياس الكفاءة الإدراكية الحركية لاى تلاميذ الصف الثالث الابتدائية لجا الباحثان الى الى الى الثي

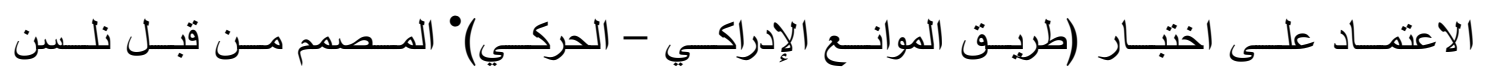

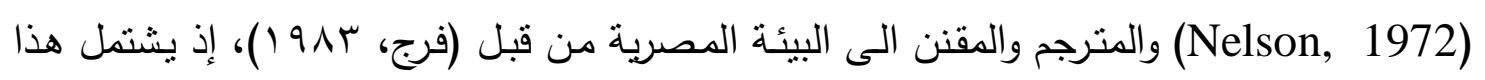
الاختبار على سبعة عناصر تختص بقياس (توافق العين والقدم وإلاحساس بالمكان وتمييز الإثكال وتوافق العين واليد والتوازن في الحركة الانتقالية والرشاقة والقدرة على حل المشكلة).

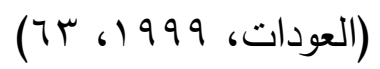

r-צ-r-1 وصف الاختبار:

يتكون اختبار (طريق الموانع الإدراكي - الحركي) من سبع محطات، المحطة الأولى الفي

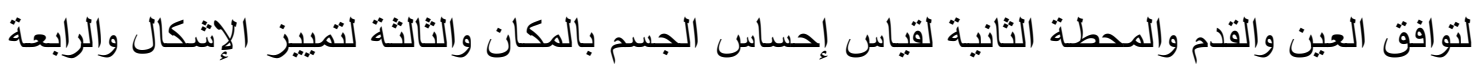

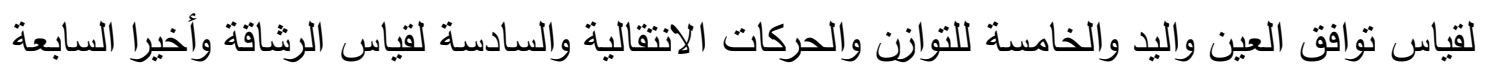

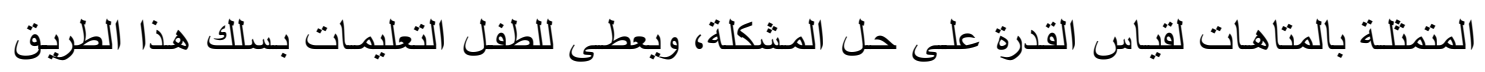

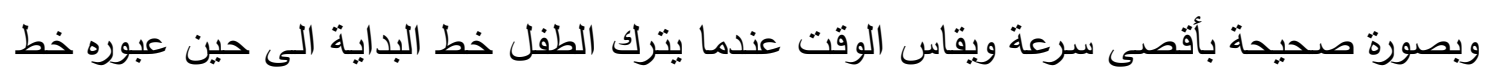
النهاية. 
لغرض التأكد من صلاحية الفقرات الواردة في أداتي البحث في قياس ما وضعت لاجله، لجا

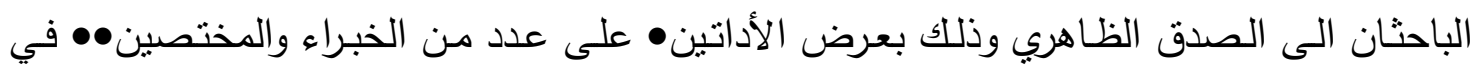

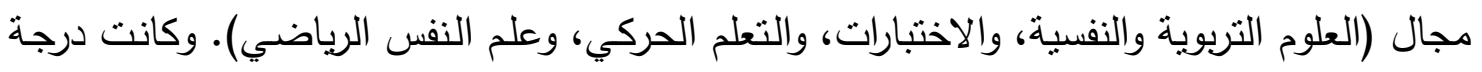

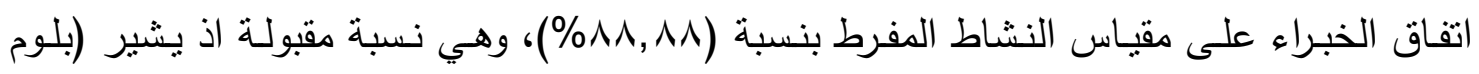

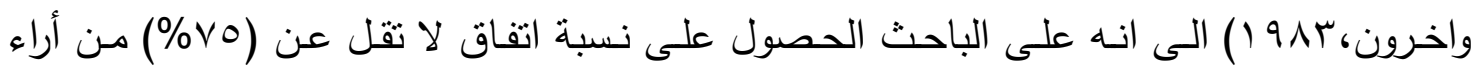

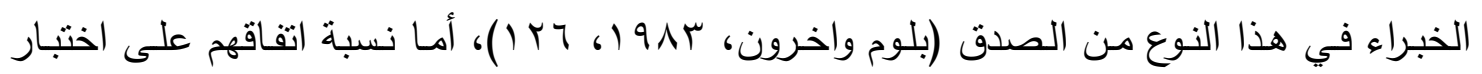

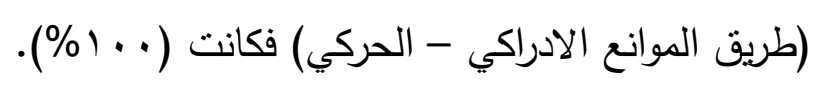

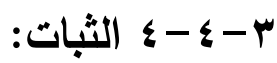

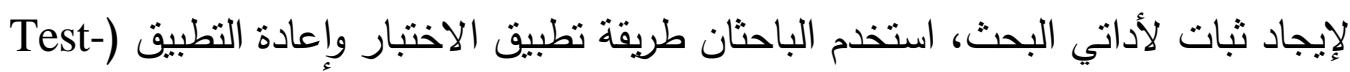

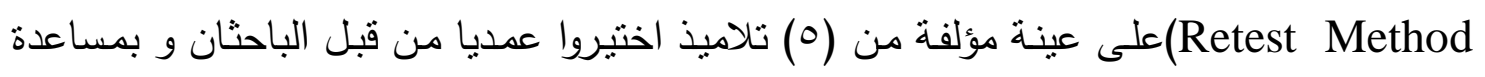

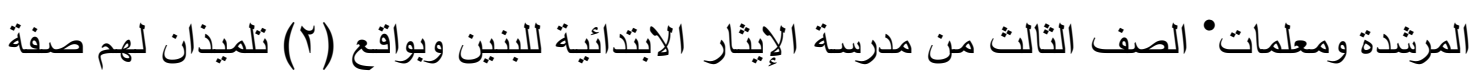

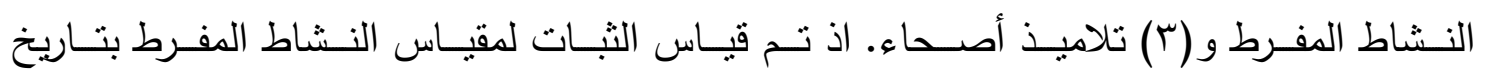

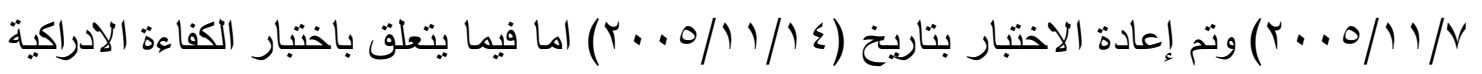

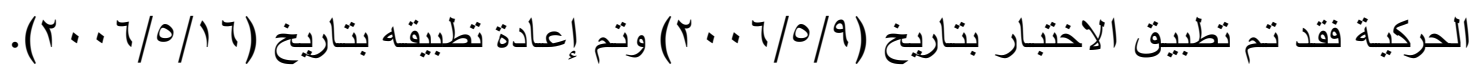

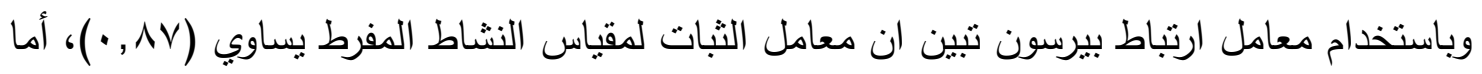

•تم عرض أداتي البحث على الخبراء والمختصين في نفس الوفت وذلك اختصارا بالوقت والجهد انظر الملحق ( ().

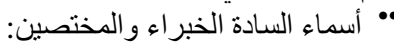
1. أ.د. كحمد يأسين و هيب/ كلية التربية - قسم العلوم التربوية و النفسية/ جامعة الموصل.

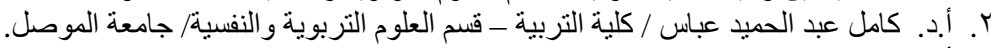

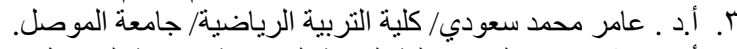

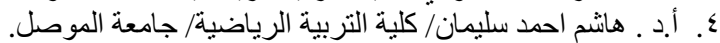

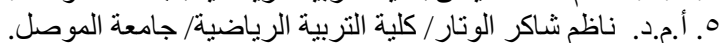

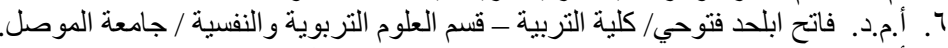

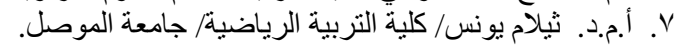

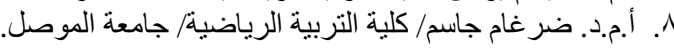

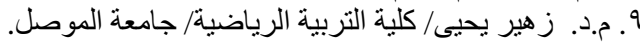

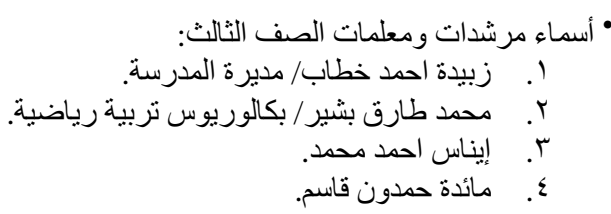


معامل الثبات لاختبار الكفاءة الادراكية الحركية (طريق الموانع الادراكي - الحركي) فكان (•^, •)، وبهذا الأجراء أصبحت أداتي البحث جاهزة للتطبيق على عينة البحث.

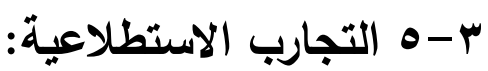

قام الباحثان بتطبيق تجربتين استطلاعيتين الأولى تتعلق بأداة النشاط المفرط اذ قام الباحثان

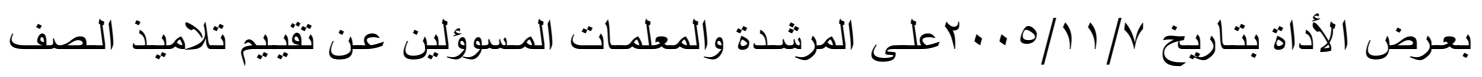

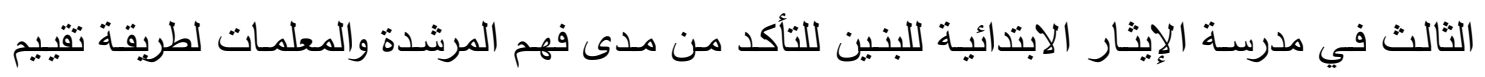

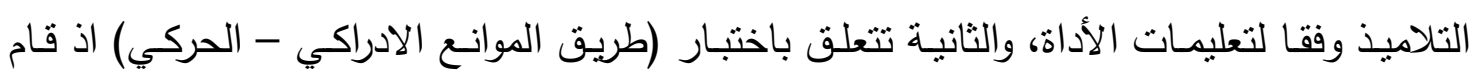

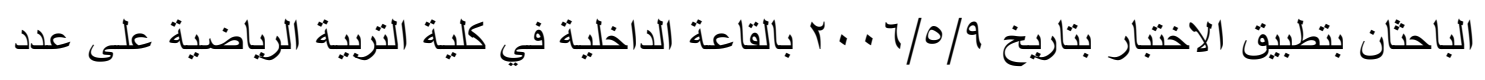

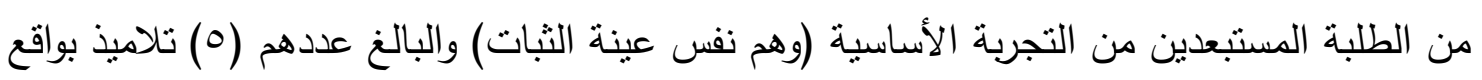

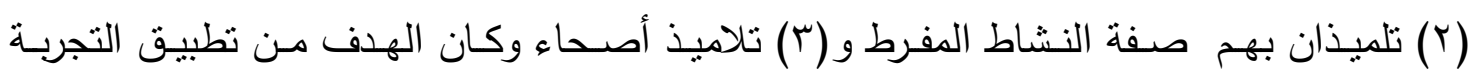
الاستطلاعية التعرف على مدى إمكانية تطبيق الاختبار بالشكل الصحيح وفقا للتعليمات المذكورة

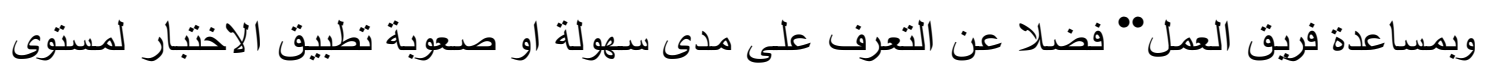
العينة والوقت المستغرق لتطبيق.

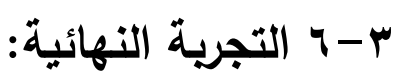

بعد ان تم تحديد الطلبـة الذين لـيهم نشاط مفرط والطلبة الأصـحاء مـن قبـل المرشدة

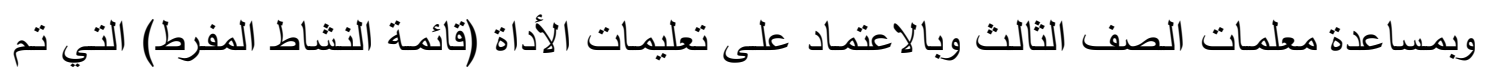

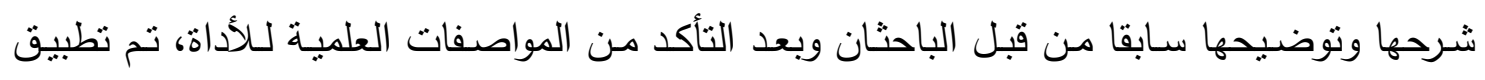

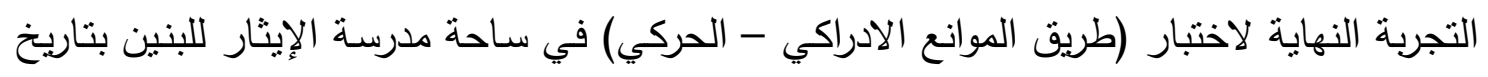

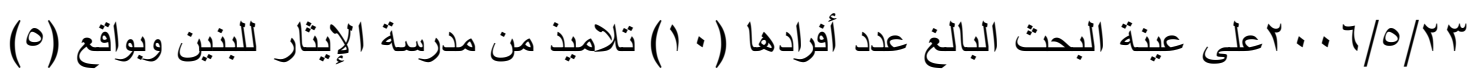

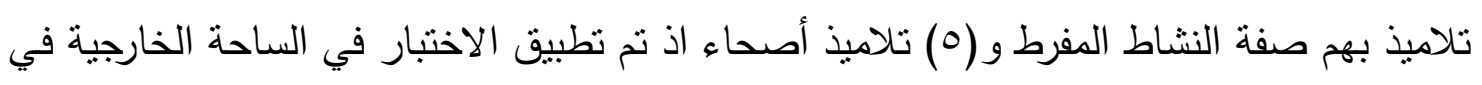
الددرسة وبمساعدة فريق العمل والكادر التعليمي في المدرسة.

\footnotetext{
• (أسماء فريق العمل المساعد: 1. . . م.م نواف عويد/ كلية التربية الرياضية/ جامعة الموصل.

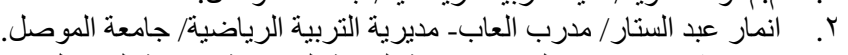

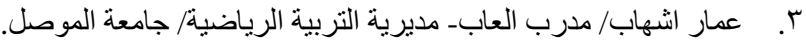

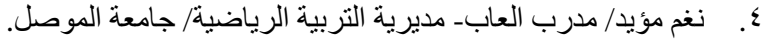

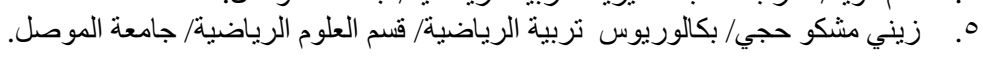




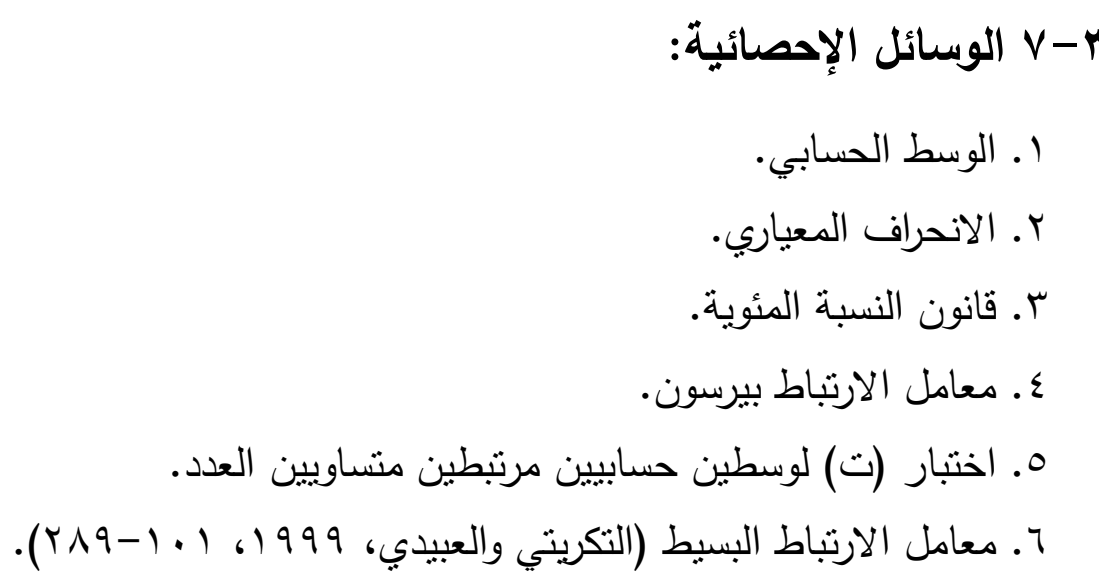

ع. عرض النتائج وتحليلها ومناقشتها:

ـ - 1 عرض وتحليا ومناقشة نتائج العلاقة بين النشاط المفرط والكفاءة الأدراكية الحركية لاى التلاميذ المفرطي النشاط والأصحاء للصف الثالث الابتائي.

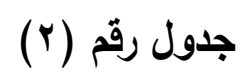

يبين المعالم الإحصائية وقيم (ر) المحسوية بين النثاط المفرط والكفاءة الإدراكية الحركية لاى التلاميذ المفرطي النثاط والأصحاء للصف الثالث الابتدائي

\begin{tabular}{|c|c|c|c|c|c|}
\hline \multirow{2}{*}{ قالمحسوية } & \multicolumn{2}{|c|}{ الكفاعة الأدراكية الحركية } & \multicolumn{2}{|c|}{ النشاط المفرط } & لالمعالم الإم \\
\hline & $\varepsilon^{ \pm}$ & سَ - س & $\varepsilon^{ \pm}$ & سَ س س س س & \\
\hline & $r, 1 \leq$ & $\wedge \vee, \vee \varepsilon$ & $1 \cdot, 4$ & זr, & تلاميذ المفرطي النشاط \\
\hline . & 9,11 & $\neg q, r \wedge$ & $\Lambda, \diamond 9$ & $\{r, \xi$ & تلاميذ الأصحاء \\
\hline
\end{tabular}

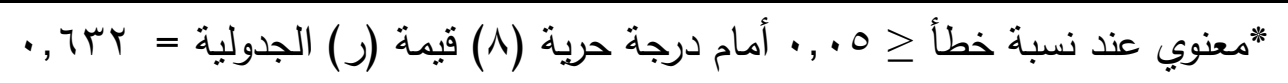

يتبين من الجدول رقم (r) ما يأتي:

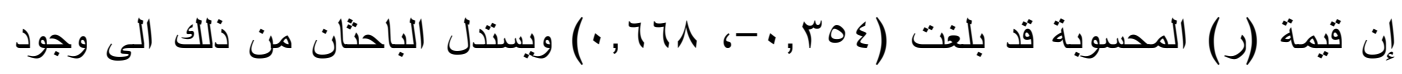

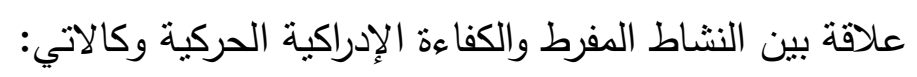


فيما يتعلق بالمجموعة التي تتصف بوجود صفة النشاط المفرط لدى التلاميذ يشير الباحثان الى وجود علاقة بين النشاط المفرط والكفاءة الادراكية الحركية إلا ان هذه العلاقة لا تصل الى المعنوية وبعزو الباحثان هذه النتيجة الى ان التلاميذ ذوي النشاط المفرط تمكنوا من أداء اختبار الكفاءة الإدراكية الحركية بصورة صحيحة ولكن قلة التركيز التي كانت لديهم أثرت سلبيا على زمن أداء الاختبار مقارنة بالأصحاء وبدل ذلك الى ان تلاميذ المفرطي النشاط هم ليسو تلاميذ معاقين عقليا

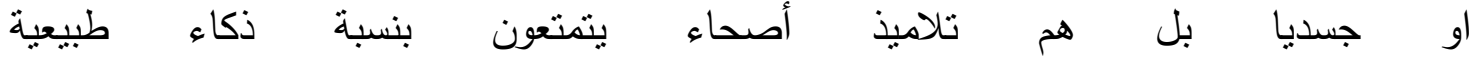
(Hetherighton \& Park, 1988, P.377) ان هناك مجموعة من العوامل الذاتية الداخلية او مجموعة من العوامل الخارجية المتصلة بالبيئة المادية والاجتماعية التي نشا بها التلاميذ أثرت سلبيا على الجوانب الحركية والانفعالية وعلى السلوك الاجتماعي لديهم اذ يكون التلاميذ انطباعا مهماً عن انفههم من خلال هذا الجانب من جوانب شخصيتهم المتمنت بمستوى انتباههم من ناحية قصوره ونتنته وقلة تركيزهم والذي بدوره اثر سلبيا على سلوكهم من ناحية توافقهم مع ذاتهم وتكيفهم مع الآخرين وعلى حركاتهم وقدراتهم الإدراكية الحركية مقارنة بالتلاميذ الأصحاء والمتمثلة بحركات غير مرغوب بها وغير هادفة او غير ثابتة والتي هي أكثر ما يميز التلميذ المفرط النشاط لذا فان إدراك التلاميذ للمواقف المختلفة التي تتضمن القدرة على استخدام جانبي الجسم الأيمن والأيسر والقدرة على استخدام الجسم وعلاقته بالمكان او الأشياء، والقدرة على تقليد الحركات المرئية باستخدام أجزاء جسمه، والتوافق بين العين واليد والعين والقدم، والتمييز السمعي في قدرة التلميذ على التحرك وأداء الحركات بسهولة وفقا لإيقاعها، وإدراك باءكاء الأشكال المختلفة وحل مشكلات النماذج الحركية وابتكار بعض الحركات، فضلا عن قدرته على التعلم سيكون اقل من التلاميذ العاديين لنفس المرحلة العمرية، وهذا ما يؤكده (راتب،999 1 ) بان النمو الحركي عند التلميذ يمنل عملية منكاملة مع جوانب السلوك المختلفة الأخرى، بل ان العلاقة فيما بين هذه الجوانب علاقة وثنقة ومتذاخلة، حيث ان النمو الحركي والنمو العقلي والنمو الانفعالي Koffka يتأثز كل منها بالأخر ويؤثز فيه (راتب،999 1، 7٪)، كما أكد ذلك كل من كوفكا وكهل Kohler بان الكائن الحي يعيش في وسط بيئة اجتماعية ومادية معينة وان أي تغيير في عناصر هذه البيئة يسبب للكائن الحي الشعور بالقلق والتوتر، ولا يزول هذا التونز الا اذا قام الكائن

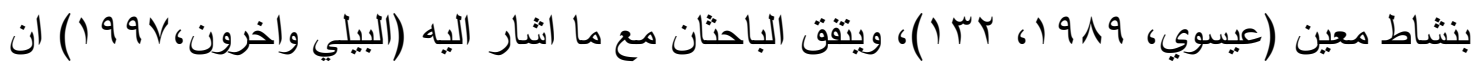
التلاميذ مفرطي النشاط لا يعانون من الحركة الزائدة فقط بل أيضا من صعوبة في الاستجابة بشكل 
مناسب ومن العمل على تحقيق أهدافهم وعدم القدرة على ضبط سلوكهم ولو لفترة قصيرة وهذه

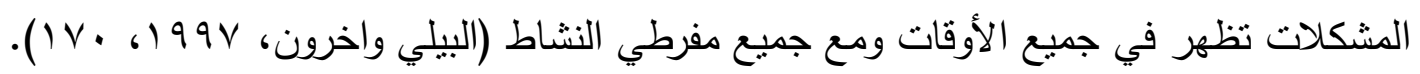

أما فيما يتعلق بالتلاميذ الأصحاء فقد أثنارت نتائج الدراسة الحالية بوجود علاقة بين النشاط الغير المفرط والكفاءة الادراكية الحركية وان هذه العلاقة تصل الى المعنوية ويعزو الباحثان هذه النتيجة الى ان التلاميذ الأصحاء تمكنوا من أداء اختبار الكفاءة الادراكية الحركية بصورة صحيحة وبزمن جيذ ويعود ذلك الى العوامل الذاتية الداخلية او العوامل الخارجية المتصلة بالبيئة المادية والاجتماعية التي نثا بها التلاميذ الأصحاء أثرت ايجابيا على الجوانب الحركية والانفعالية وعلى التى السلوك الاجتماعي والمستوى المعرفي لديهم والذي اتاحا لهم فرص النمو النفسي والعاطفي والاجتماعي والعقلي الطبيعي فضلا عن نمو قدراتهم الادراكية والحركية بصورة سريعة ونشطة من خلال إعطاء الحرية لهم بالحركة وبالتعبير عن ميولهم ورغباتهم والتالي وصول التلاميذ الى مستوى معين من النضوج مما يعطي فرص اللتعلم والممارسة والتفاعل بجوانب منتوعة من الحياة

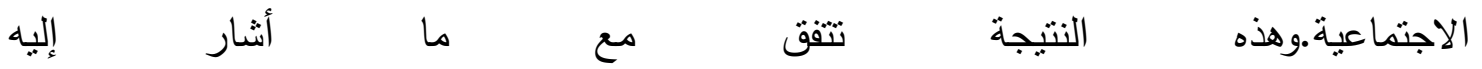
(الخولي وراتب،9191) ان إعطاء حرية الحركة والتعبير يساعد التلاميذ في تتمية ملاحظاتهم

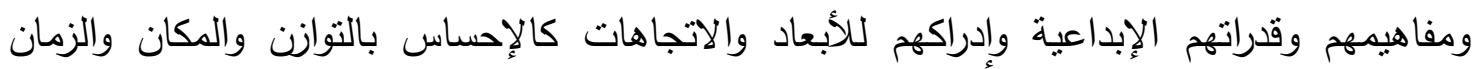
واكتسابهم المعرفة بكل مستوياتها فيعود على سلوكهم المنطقي وحل المشكلات وإصدار الإداد أحكام

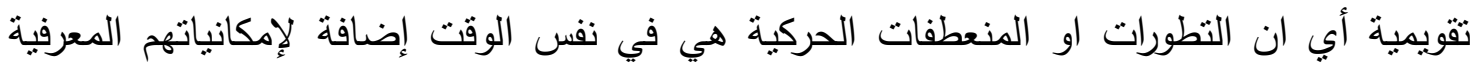

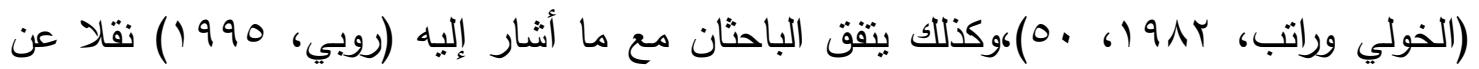

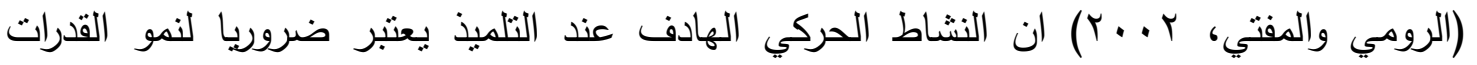
الادراكية- الحركية وللنمو المعرفي بوجه عام وخاصة في مرحلة الطفولة وان القصور في نمو

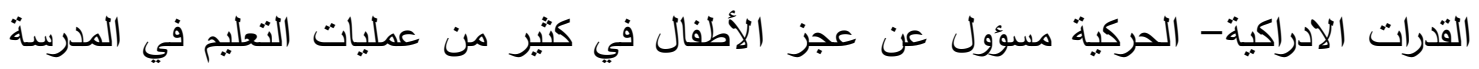

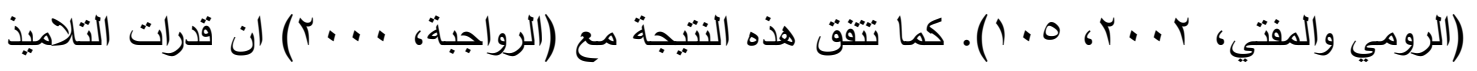
تزداد بالإكثار من لعب الأدوار بصورة واثقة وفي مواقف مختلفة ستمد التلاميذ برصيد هائل من النا المعلومات النفسية والحسية الملائمة عندما يواجهون مواقف يتطلب حلها القدرة على الثقة بالنفس لإنس

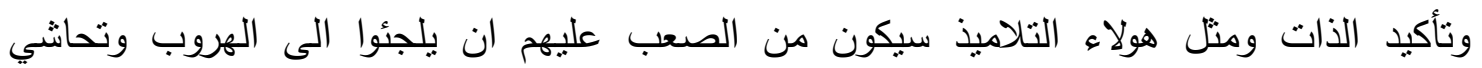

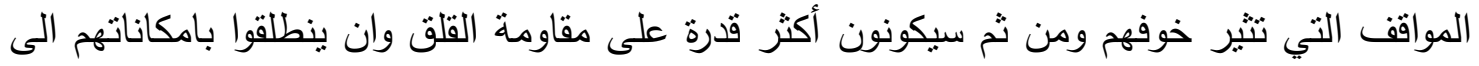

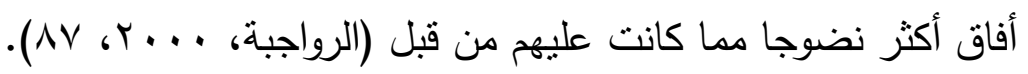




\section{0 - ـ الاستنتاجات والتوصيات:

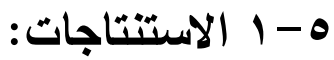

ا ـ ان التلاميذ الذين لديهم صفة المفرطي النشاط لديهم مستوى من الكفاءة الادراكية الحركية ولكن هذا المستوى لا يصل الى المعنوية.

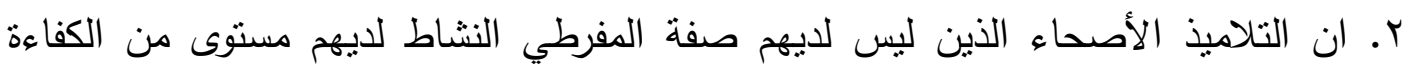
الادراكية الحركية وهذا المستوى يصل الى المعنوية.

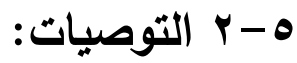

1. التشخيص المبكر للتلاميذ المفرطي النشاط ومحاولة التعاون مع الآباء في اعتماد برامج

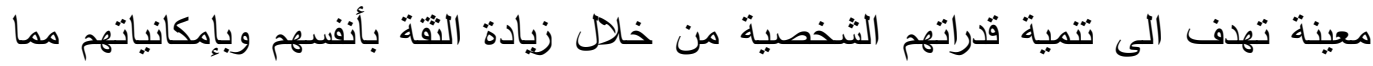
يساعد في تعديل سلوكهم ويزيد من مقدرتهم على تقبل المواد النظرية.

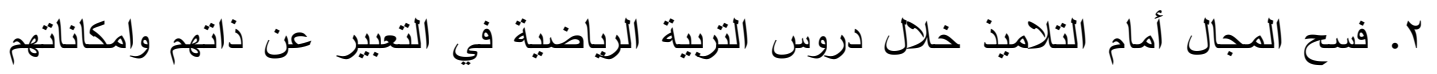

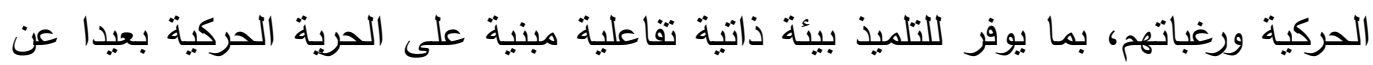
التقليدية في التنفيذ الحركي وتئي r. توعية الآباء بأهمية الهوايات والرياضة البدنية والترويح عن النفس او الاثتراك في الأنشطة

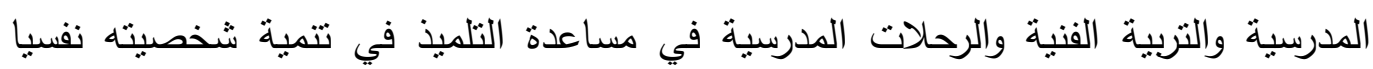

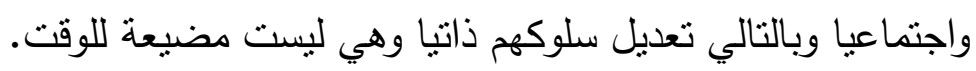

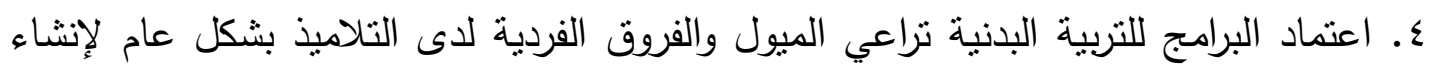

$$
\begin{aligned}
& \text { جيل سليم فعال ومنتج. } \\
& \text { ه-r المقترحات: }
\end{aligned}
$$

ه. إجراء دراسة العلاقة بين التلاميذ المفرطي النشاط في الكفاءة الادراكية الحركية للمراحل الدراسية المختلفة. T. إجراء دراسة العلاقة بين الكفاءة الادراكية الحركية والتحصيل الدراسي للمراحل الدراسية المختلفة. 


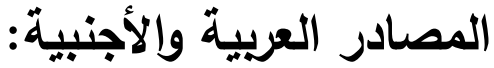

1. بلوم، بنيامين. س، وآخرون (r (191)): تقييم تعلم الطالب التجميعي والتكويني، ترجمة، محمد

$$
\text { امين المفتي وآخرون، ماكروهيل، القاهرة. }
$$

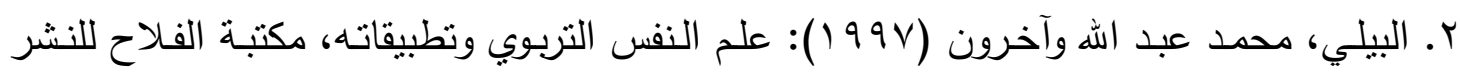

$$
\text { والتوزيع، قسم علم النفس، جامعة الأمارات. }
$$

r. التكريتي، وديع ياسين والعبيدي، حسن محمد (999 (19)): التطبيقات الإحصائية واستخدامات

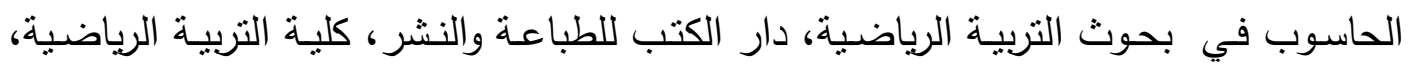

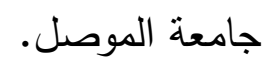

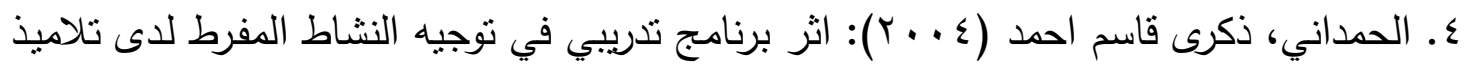
المرحلة الابتدائية، رسالة ماجستير غير منشورة، كلية التربية، جامعة الموصل.

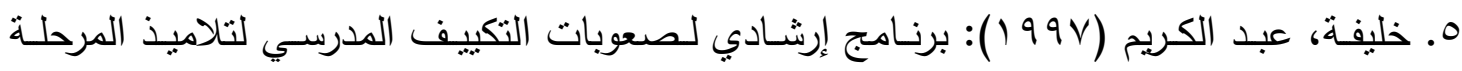
الابتدائية، رسالة ماجستير غير منشورة، كلية التربية، جامعة المستتصرية.

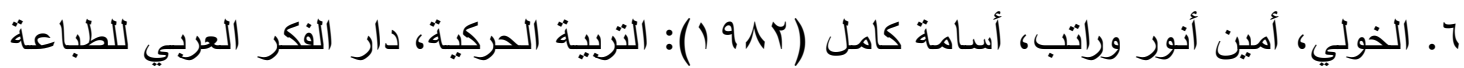

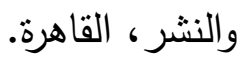
V. الخولي، أمين أنور وراتب، أسامة كامل (ع 99 (1): التربية الحركية للطفل، دار الفكر العربي للطباعة والنشر ، ط ז، القاهرة. ^. الدباغ ، فخرالدين وآخرون (r/911): اختبار رافن للمصفوفات المتتابعة، المقنن للعراقيين، مديرية

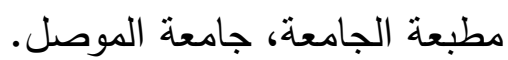

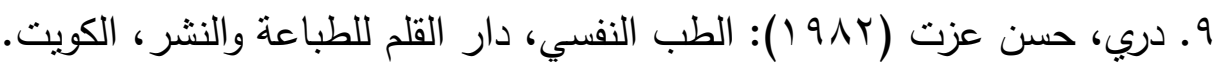
• الفكر العربي للطباعة والنشر، كلية التربية الرياضية للبنين، جامعة حلوان.

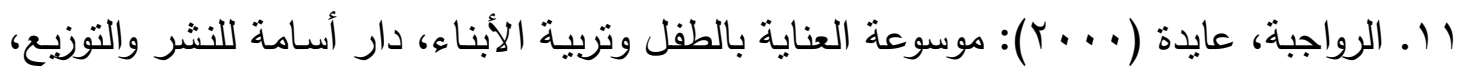
عمان، الأردن.

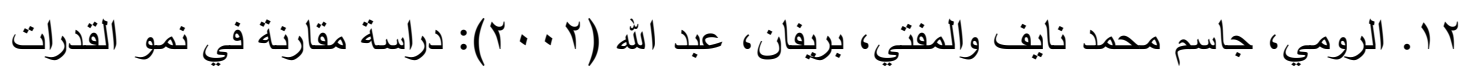

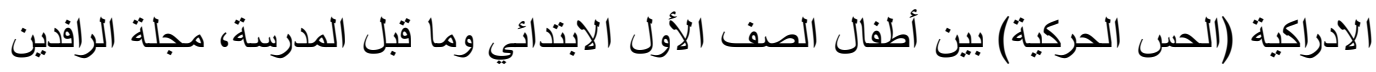

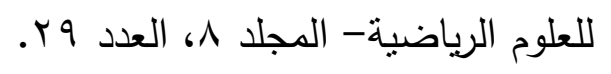




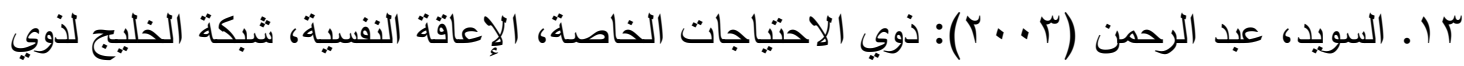

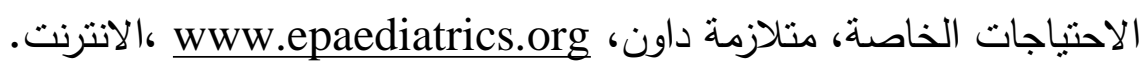

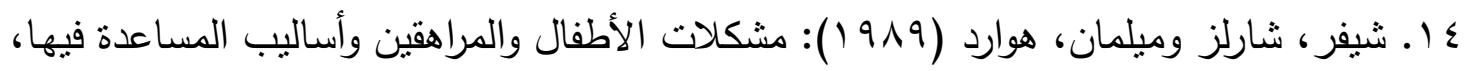
ترجمة نسيمة عواد، منشورات الجامعة الأردنية، عمان. 10. طنطاوي، احمد، وعجلان، عثمان (990 ()): اثر بعض العوامل المزاجية والمعرفية المرنبطة بقصور الانتباه لدى الأطفال والمراهقين، ، دار الفكر العربي، القاهرة.

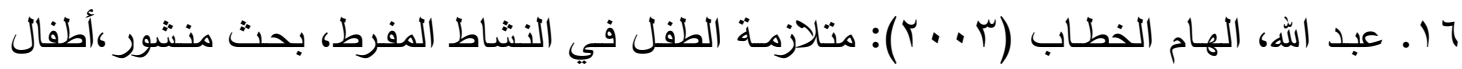
الخليج ذوب الاحتياجات الخاصة، www.galfkids.com ، (الانترنت).

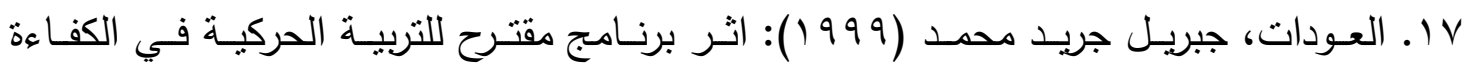
الادراكية- الحركية لدى طلبة الصف الثالث من مرحلة التعليم الأساسي، رسالة ماجستير غير منشورة، كلية التربية الرياضية، جامعة الموصل.

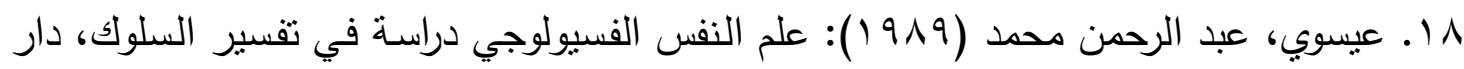
المعرفة الجامعية، كلبة الآداب، جامعة الإسكندرية.

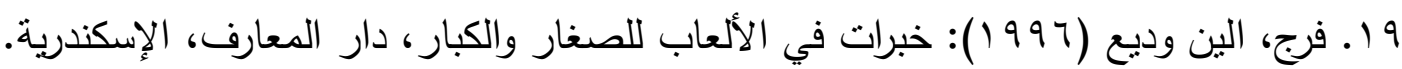

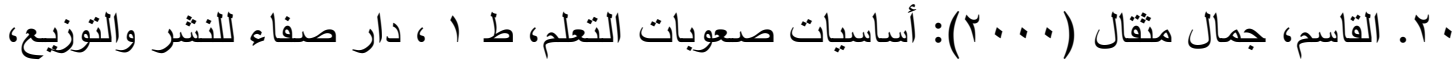

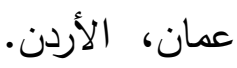

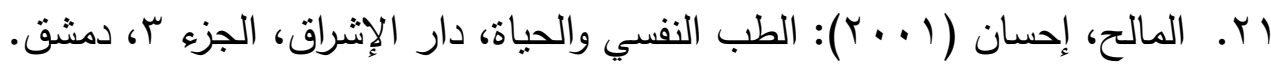

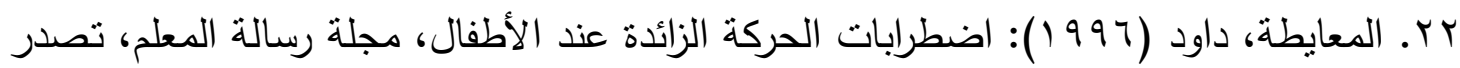

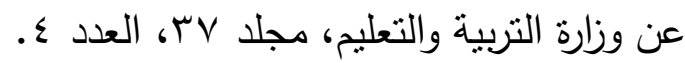

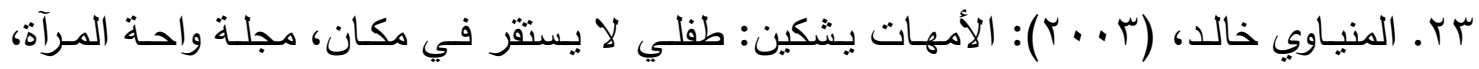
القاهرة، إخوان أون لاين، www.ikhwanonline. com ،(الانترنت).

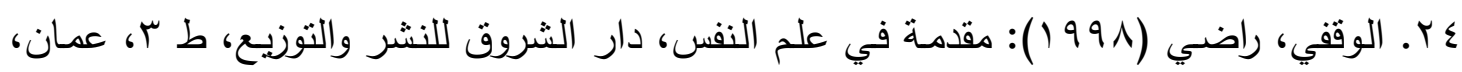

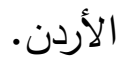

25. Barkley, R.A. (1997): "Behavioural inhibition, Sustained Attention, and Executive Functions Construction a Uniform Theory of ADHD", Psychological Bulletin, 
26. Buss, Arnold H. (1978):"Temperamental Theor andPersonality Development", New York, John Wiley \& Sons.

27. Hetherighton, E. Maris and Park, Ross D. (1988): "Child Psychology", 3rd. ed., New York, Random House.

28. Lambert, Nadine M. and Sandoval, Jonathan (1986): "The Prevelance of Learning Disabilities in Sample of Children Considered Hyperactive", Journal of Abnormal Psychology, Vol.8, No.1.

29. Ross, Dorothea and Ross, Scheila (1976): "Hyperactivity Research", Theory and Action, New York: John Wiley \& Sons.

30. Wender, P.H., ADHD (2000): "Attention-deficit Hyperactivity disorder in Children and Adults", New York: Oxford University Press.

31. Williams, Joyce Woifgong and Stith, Margoric. Middle (1980): "Childhood Behaviour and Development", 2nd. ed., London: Collier Macmillan Publishers. 


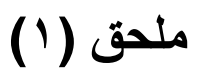

جامعة الموصل

كلية التربية الرياضية

\author{
بسم الله الرحمن الرحيم \\ استبيان أراء الخبراء
}

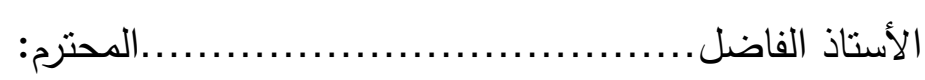

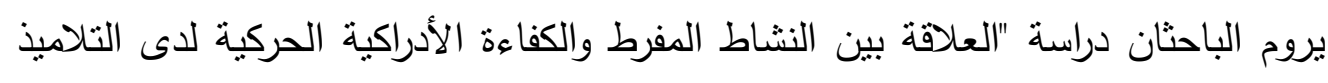

المفرطي النشاط والأصحاء للصف الثالث الابتدائي". وقد اعتمد الباحثان على قائمة المظاهر السلوكية للأطفال ذوي النشاط المفرط التي تم الحصول عليها من دراسة (ألصالحي، .... والمعدة من قبله في التعرف على المظاهر السلوكية لتلاميذ المرحلة الابتدائية من ذوي النشاط المفرط. كما اعتمد الباحثان على اختبار (طريق الموانع الأدراكي- الحركي) المصمم من قبل (Nelson, I qVY) تتمتعون به من خبرة ومكانة علمية في هذا المجال ولما لأرائكم من دور فاعل، لذا نرجو منكم إبداء رأيكم حول مدى صلاحية أداتي البحث للغرض أعلاه.

\section{مع جزيل الثكر والأمتنان}

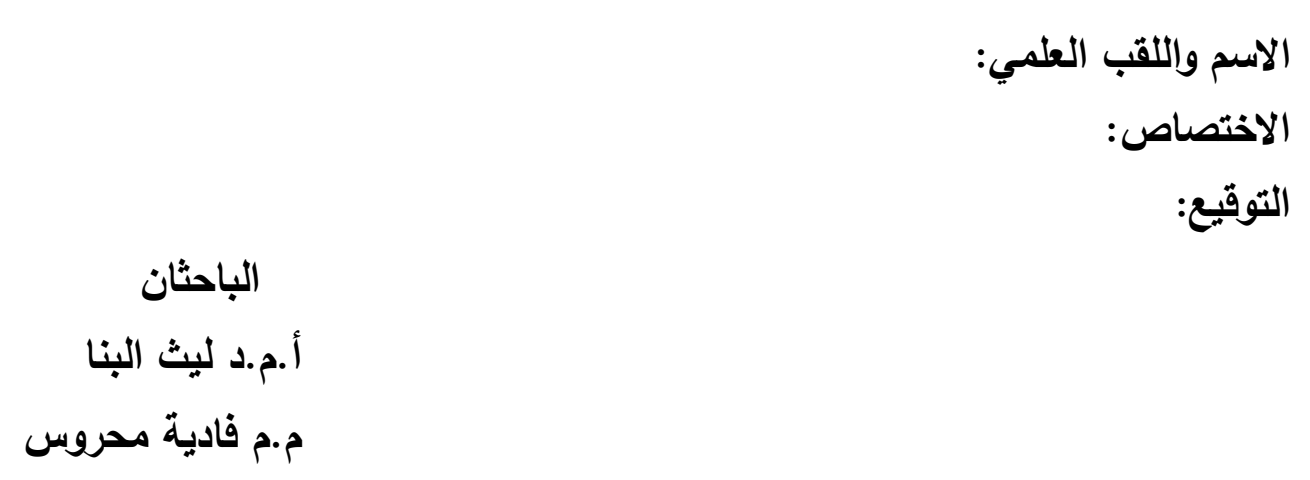

or 


\section{قائمة المظاهر السلوكية}

\begin{tabular}{|c|c|c|c|c|}
\hline 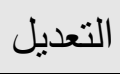 & غير صالحة & صالحة & المظاهر السلوكية & $ت$ \\
\hline & & & يحرك أعضاء جسمه بشكل مفرط & 1 \\
\hline & & & لا يستقر في المكان المخصص له & r \\
\hline & & & حركات جسمه غير منتظمة وغير موزونة & $r$ \\
\hline & & & يكتب ويرسم على الجدران بالطباشير & $\varepsilon$ \\
\hline & & & يتسلق ألاماكن المرتفعة ويقفز منها & 0 \\
\hline & & & يخرج من الصف حال سماع صوت الجرس قبل خروج المعلم & 7 \\
\hline & & & يتتقل في الصف من محل لأخر بدون استئذان المعلم & V \\
\hline & & & يبدي أعذارا مختلفة كحجة للخروج من الصف & $\wedge$ \\
\hline
\end{tabular}

\begin{tabular}{|c|c|c|c|c|}
\hline 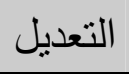 & غير صالحة & صالحة & المظاهر السلوكية & $ت$ \\
\hline & & & يقاطع المعلم في أثناء شرح الدرس دون استئذان & 1 \\
\hline & & & يهمل التعليمات والأنظمة المدرسية & r \\
\hline & & & يهمل نظافة جسمه وهندامه ولوازمه المدرسية & r \\
\hline & & & يستهزئ بزملائه داخل الصف وخارجه & $\varepsilon$ \\
\hline & & & لا يميل تلاميذ الصف لعقد صداقة معه & 0 \\
\hline & & & يستخدم ألفاظا بذيئة في تعامله مع زملائه & 7 \\
\hline & & & يعبث بحاجيات زملائه دون استئذان & V \\
\hline & & & يتصف بالعدوانية في أثناء تعامله مع زملائه & $\wedge$ \\
\hline & & & يمارس عادات غير مرغوبة كمص الإصبع وقضم الأظافر & 9 \\
\hline & & & كثيراً ما يشكو زملاؤه منه للمعلم & $1 \cdot$ \\
\hline & & & يقوم بحركات لجلب انتباه المعلم وزملائه & 11 \\
\hline & & & نطقه غيرواضح ويرتبك في كلامه & ir \\
\hline
\end{tabular}




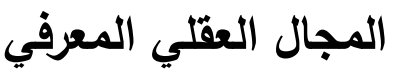

\begin{tabular}{|c|c|c|c|c|}
\hline 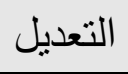 & غير صالحة & 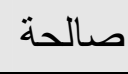 & المظاهر السلوكية المية & $ت$ \\
\hline & & & | يعاني من تشتت الانتباه في أثناء الدرس & 1 \\
\hline & & & لألا يستطيع تتييت ذهنه على موضوع واحد وإنما ينتقل من فكرة & r \\
\hline & & & يسرح في خيالات وأفكار غريبة في أثناء الدرس & r \\
\hline & & & |يعاني من صعوبة متابعة المعلم في أثناء القراءة & $\varepsilon$ \\
\hline & & & |يصعب عليه فهم الأشياء التي يسمعها & ० \\
\hline & & & | يصعب عليه فهم الأشياء التي يراها & 7 \\
\hline & & & | يعاني من صعوبة الربط بين فقرات الموضوع الواحد & v \\
\hline & & & يعاني من صعوبة استيعاب المفاهيم الرياضية البسيطة & $\wedge$ \\
\hline & & & نطقه غير واضح ويرتبك في كلامه مع المعلم & 9 \\
\hline & & & |يواجه المشكلات البسيطة والمعقدة بأسلوب عدواني & 1. \\
\hline
\end{tabular}

\section{اختبار طريق الموانع الأدراكي الهركي:}

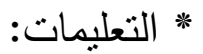

يعطى للطفل التعليمات بان يسلك هذا الطريق وبصورة صحيحة بأقصى ما يسنطيع وتبدأ ساعة

الإيقاف عندما يترك الطفل خط البداية ويتوقف عندما يعبر خط النهاية.

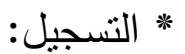

الزمن المنقضي لانتهاء الطريق بأكمله. وفي حالة ما اذا أخطا الطفل فانه يعاود البدء من

النقطة التي أخطا فيها.

1- المحطة الأولى: نوافق العين والقدم:

الأدوات: قطعة من الورق المقوى عليها أثار أقدام، المسافة بين طبعة الإقدام (Y I) بوصة.

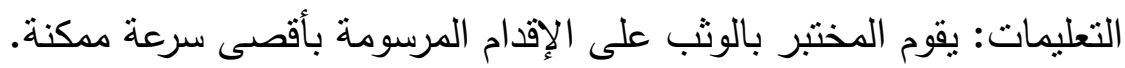

r- الهحطة الثانية: لأعلى وأسفل (إحساس الجسم بالبك الثكان): 
الأدوات: (؟) موانع وحواجز . ثلاثة موانع بارتفاع (r) قدم ونصف من الأرض وثلاثة حواجز

$$
\text { بارتفاع (r ا I) بوصة. }
$$

التعليمات: يجري المختبر بأسرع ما يمكن من أسفل الموانع ويثب من فوق الحواجز . بأل

r- الدحطة الثالثة: تميز الأثكال:

الأدوات: ترسم دوائر ومثلثات ومربعات على الأرض وقطر كل شكل منها (Y I ( ) بوصة والمسافة

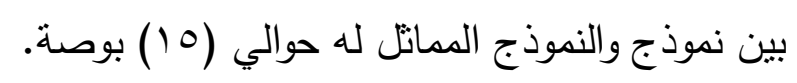

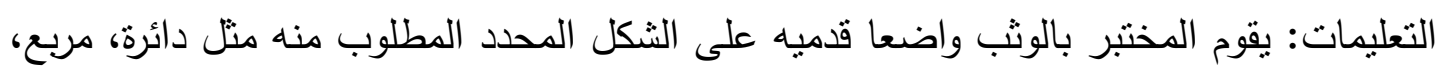

$$
\begin{aligned}
& \text { منلث، يمكن تغيير الثكل مع كل محاولة. } \\
& \text { ــ المحطة الرابعة: نوافق العين واليد: }
\end{aligned}
$$

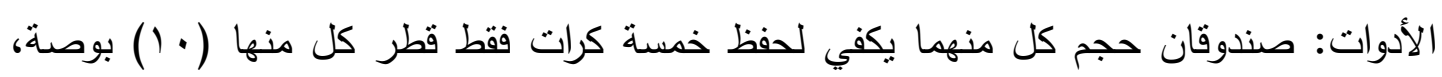

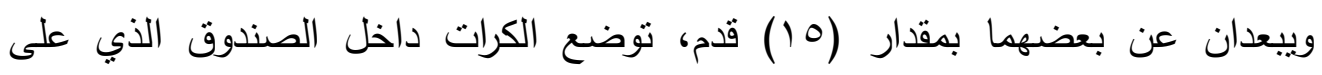

$$
\text { اليسار }
$$

النعليمات: يأخذ المختبر الكرات من الصندوق الذي على اليسار (كرة واحدة كل مرة، ويقذفها داخل

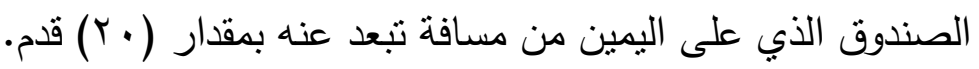

$$
\begin{aligned}
& \text { ــ المحطة الخامسة: التوازن والحركات الانتقالية: } \\
& \text { الأدوات: ثلاث مقاعد سويدية. }
\end{aligned}
$$

التعليمات: يتحرك المختبر فوق المقعد الأول جانبا يمينا بالخطوة المنزلقة ثم ينتقل الى الدقعد

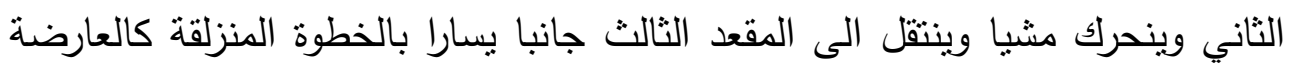

$$
\text { الأولى. }
$$

4- المحطة السادسة: رشاقة جري الأطواق:

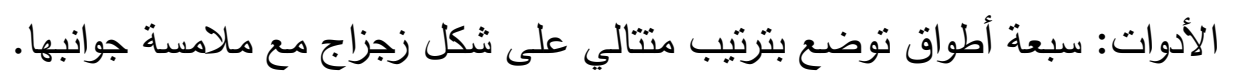

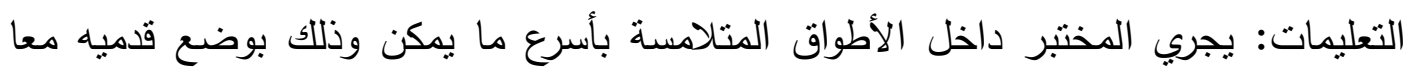

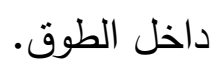

V- المحطة السابعة: المتاهة:

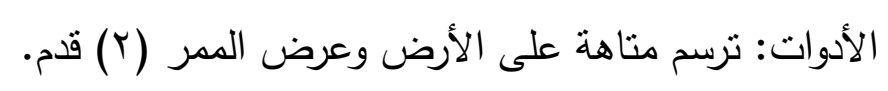

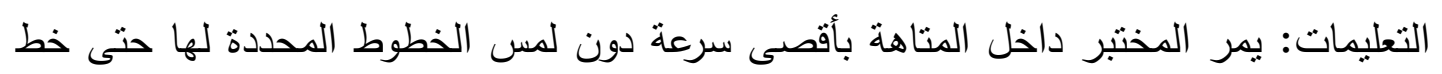




\section{مخطط الأتَّبار الادراكي- الهركي}

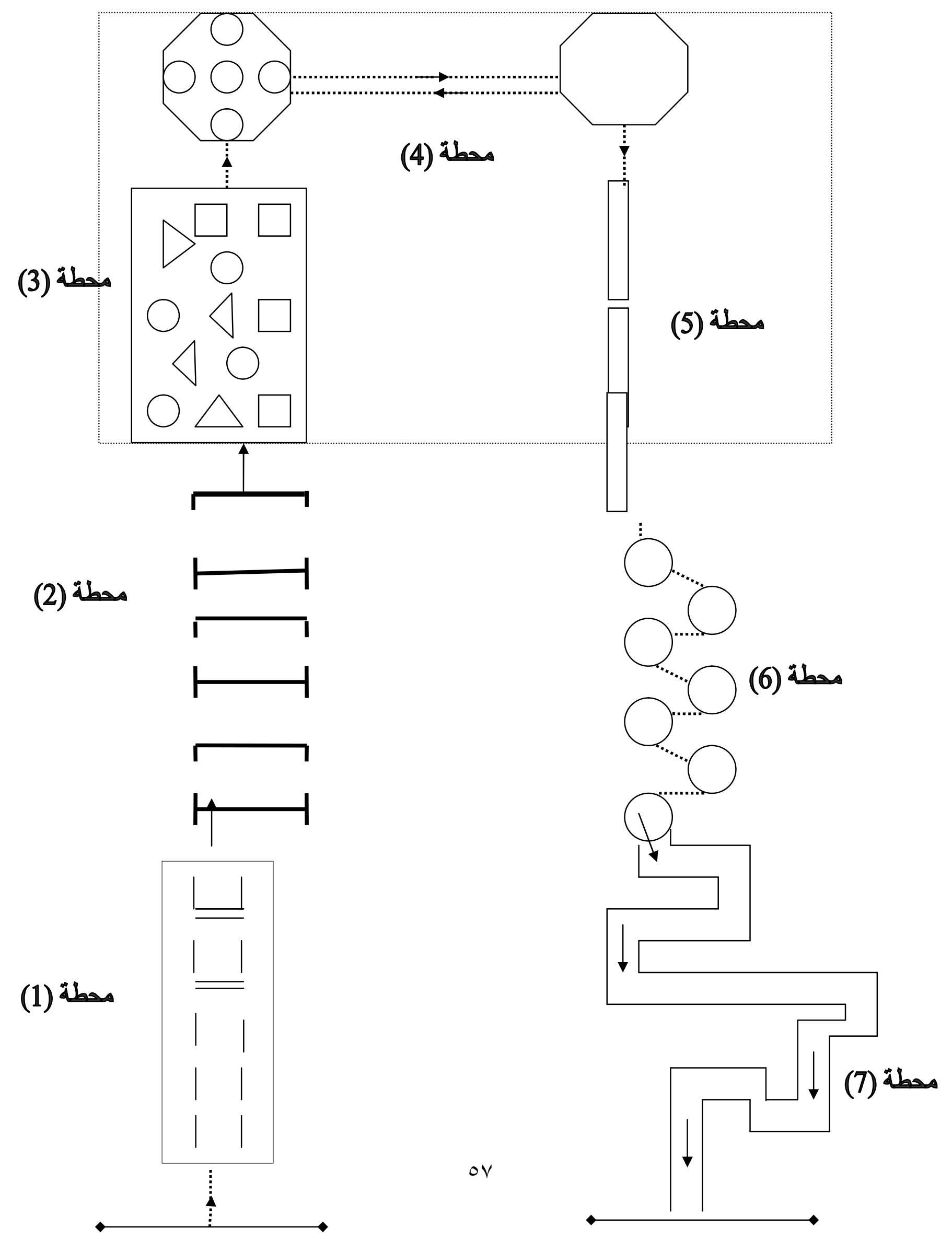

